NBER WORKING PAPER SERIES

\title{
IDENTIFYING THE EFFECT OF ELECTION CLOSENESS ON VOTER TURNOUT: EVIDENCE FROM SWISS REFERENDA
}

\author{
Leonardo Bursztyn \\ Davide Cantoni \\ Patricia Funk \\ Felix Schönenberger \\ Noam Yuchtman \\ Working Paper 23490 \\ http://www.nber.org/papers/w23490 \\ NATIONAL BUREAU OF ECONOMIC RESEARCH \\ 1050 Massachusetts Avenue \\ Cambridge, MA 02138 \\ June 2017
}

This paper supersedes a previous working paper titled, "Polls, the Press, and Political Participation: The Effects of Anticipated Election Closeness on Voter Turnout."We would like to thank Ernesto Dal Bó, Devesh Rustagi and numerous seminar participants for very helpful comments. We thank Tillmann von Carnap, Raymond Han, Peter Hong, Vasily Korovkin, Aakaash Rao, Ann-Christin Schwegmann, Abboud Masky Youssef, Sylvain Züger, and in particular Francesca Crotta and ChristophWellig, for extraordinary research assistance. HansPeter Kriesi generously shared data. Financial support from the Swiss National Science Foundation (grant 172739) is gratefully acknowledged. The views expressed herein are those of the authors and do not necessarily reflect the views of the National Bureau of Economic Research.

NBER working papers are circulated for discussion and comment purposes. They have not been peerreviewed or been subject to the review by the NBER Board of Directors that accompanies official NBER publications.

(C) 2017 by Leonardo Bursztyn, Davide Cantoni, Patricia Funk, Felix Schönenberger, and Noam Yuchtman. All rights reserved. Short sections of text, not to exceed two paragraphs, may be quoted without explicit permission provided that full credit, including $\odot$ notice, is given to the source. 
Identifying the Effect of Election Closeness on Voter Turnout: Evidence from Swiss Referenda Leonardo Bursztyn, Davide Cantoni, Patricia Funk, Felix Schönenberger, and Noam Yuchtman NBER Working Paper No. 23490

June 2017

JEL No. D72,P16

\begin{abstract}
We provide evidence of a causal effect of anticipated election closeness on voter turnout, exploiting the precise day-level timing of the release of Swiss national poll results for high-stakes federal referenda, and a novel dataset on daily mail-in voting for the canton of Geneva. Using an event study design, we find that the release of a closer poll causes voter turnout to sharply rise immediately after poll release, with no differential pre-release turnout levels or trends. We provide evidence that polls affect turnout by providing information shaping beliefs about closeness: first, the introduction of Swiss polls had significantly larger effects in politically unrepresentative municipalities, where locally available signals of closeness are less correlated with national closeness. Second, the effects of close polls are largest where newspapers report on them most. Counterfactual exercises suggest the importance of polls and reporting on polls in shaping election outcomes.
\end{abstract}

Leonardo Bursztyn

Department of Economics

University of Chicago

1126 E. 59th Street

Chicago, IL 60637

and NBER

bursztyn@uchicago.edu

Davide Cantoni

Seminar für Wirtschaftsgeschichte

University of Munich

80539 Munich

Germany

and CEPR

davide.cantoni@econ.lmu.de

Patricia Funk

Università della Svizzera Italiana

Via Giuseppe Buffi 13

6904 Lugano

Switzerland

patricia.funk@usi.ch
Felix Schönenberger

Università della Svizzera Italiana

Via Giuseppe Buffi 13

6904 Lugano

Switzerland

felix.schoenenberger@usi.ch

Noam Yuchtman

London School of Economics

Houghton St.

London WC2A $2 \mathrm{AE}$

United Kingdom

and CEPR

and also NBER

n.yuchtman@1se.ac.uk 


\section{Introduction}

Voter turnout is among the political behaviors of greatest interest to social scientists, shaping election outcomes and thus public policy. Yet, there is a surprising lack of clear, causal evidence for one of the most widely-studied drivers of turnout: a voter's response to anticipated election closeness, which is at the heart of voting models dating back to Downs (1957), and the subject of more than 100 empirical studies (summarized in Cancela and Geys, 2016). ${ }^{1}$ On the one hand, observational studies generally find significant, positive correlations between election closeness and voter turnout, but causal inference is undermined by concerns that underlying issue type or the behavior of the political "supply side" (e.g., political advertising) may drive the results. ${ }^{2}$ On the other hand, recent field experiments providing far more credible tests (Gerber and Green, 2000, Bennion, 2005, Dale and Strauss, 2009, and particularly Enos and Fowler, 2014, and Gerber et al., 2020) find no effect of anticipated election closeness on voter turnout.

In this paper we provide evidence of a significant, causal effect of anticipated election closeness on voter turnout. In contrast to existing observational studies we exploit a credible quasiexperiment arising from the release of polls. In contrast to field experimental research our analysis is less exposed to concerns that results might be driven by common information sets outside of the experiment. ${ }^{3}$ Specifically, we exploit the precise day-level timing of the release of Swiss national poll results for 52 high-stakes federal referenda, and a novel dataset on daily mail-in voting for the canton of Geneva. ${ }^{4}$ Using an event study design — thus holding fixed the issue type - we find that the release of a closer poll causes voter turnout to sharply rise immediately after poll release. A one-standard deviation closer poll increases voter turnout by a statistically significant 0.4 percentage points in each of three days immediately following the poll's release. We find that turnout rates are no different in levels or trends in the days prior to the release of close polls, suggesting that the information contained in the polls was not anticipated.

Importantly, we can exclude that these results are caused by a differential response of the "supply side", i.e. political advertisements. First, the absence of pre-trends suggests that the supply

\footnotetext{
${ }^{1}$ Such a causal effect might arise for a variety of theoretical reasons, from (perhaps imperfect) instrumental calculations of costs and benefits (Myatt, 2015), to interactions of election closeness with social preferences (e.g., DellaVigna et al., 2016) or with the intrinsic utility from voting (e.g., Riker and Ordeshook, 1968, Brennan and Buchanan, 1984, Schuessler, 2000, Feddersen and Sandroni, 2006, and Ali and Lin, 2013).

${ }^{2}$ See, for example, Barzel and Silberberg (1973), Cox and Munger (1989), Matsusaka (1993), Shachar and Nalebuff (1999), and Kirchgässner and Schulz (2005).

${ }^{3}$ Common information sets outside the experiment would tend to produce convergence in posterior beliefs regarding closeness at the time of the elections - and therefore similar turnout levels — between treatment and control groups. Gerber et al. (2020) implement a particularly elegant design, experimentally shocking voters' beliefs, and eliciting posterior beliefs to document a "first stage" effect of the intervention. However, because the first stage is measured two weeks before the election itself, there remains the possibility that posterior beliefs regarding closeness converged between treatment and control groups by the time the voting decision was made.

${ }^{4}$ The vast majority - 90\% — of votes cast in Geneva for the referenda studied are mail-in ballots. Note that we use the term "referenda" throughout to refer to federal referenda and initiatives. We discuss the institutional details of our setting in Section 2.
} 
side was not differentially active prior to the release of close polls. Nor does an endogenous supply side response to the close polls, in the days following their release, account for our findings: we observe significant effects of close polls on votes counted the day immediately after a close poll was released - before the supply side could have affected turnout. Moreover, we can directly test for a supply side response, counting political ads in newspapers (the primary form of political advertising in Switzerland, as TV ads are prohibited). We find that, consistent with close polls meaningfully affecting political beliefs and behavior, there is some evidence of a supply side response: ads significantly increase following a close poll. But, this response appears only three days after the release of a closer poll (potentially affecting votes counted four days after poll release), well after voter turnout already significantly increased.

We next examine data from across Switzerland testing several auxiliary predictions and providing evidence that polls affect turnout by providing information shaping beliefs about closeness. First, we propose a simple conceptual framework in which, in the absence of polls, voters gauge an upcoming election's closeness by "locally sampling" among individuals in their municipality. This will yield correct beliefs only if the municipality's closeness is correlated with closeness at the national level (i.e., if the municipality is "representative"). In unrepresentative municipalities, it is difficult for individuals to condition their turnout decision on national-level vote closeness, since their locally available signal is uninformative. In contrast, even in the absence of polls, individuals in politically representative municipalities are able to condition their turnout decision on nationallevel vote closeness, as their local signal is informative. When national polls are introduced, information on national-level closeness becomes widely available, allowing individuals in both representative and unrepresentative municipalities to condition their turnout on national-level closeness. Exploiting the introduction of polls in Switzerland in 1998, we test whether polls' introduction indeed had a larger effect on voter turnout in unrepresentative municipalities. Consistent with our predictions, we find that prior to 1998, municipalities representative of Switzerland exhibit some association between closeness and turnout, while unrepresentative municipalities do not. Following the introduction of polls, the closeness-turnout gradient increases differentially in unrepresentative municipalities, is positive and highly significant, and nearly identical in the two sets of municipalities.

Next, we examine whether close polls differentially increase turnout when they receive more coverage in local media. Using a canton $\times$ vote panel, we study the effect of within-election variation in the coverage of the national poll by newspapers read by the citizens of a canton. Importantly, newspapers were the primary source of political information among Swiss voters throughout the period we study. ${ }^{5}$ Controlling for canton and vote fixed effects - and thus purging our estimates

\footnotetext{
${ }^{5}$ The nationally-representative "VOX survey," conducted following each vote, asks Swiss citizens a broad range of political questions. One of these directly asks, "Through which media did you orient yourself and learn about the pros and cons of the last vote?" In each survey, newspapers were the most frequent selection, with around $80 \%$ of respondents indicating the importance of newspapers as a source of political information. See Online Appendix Figure A.1.
} 
of the effects of a fixed (national-level) "issue type" driving turnout - we find that greater cantonal newspaper coverage of close polls significantly increases voter turnout. A one standard deviation increase in the newspaper coverage of a poll that is one standard deviation closer than the mean increases turnout by around 0.5 percentage points. To address concerns about endogenous local coverage of polls, we exploit a canton's arguably "incidental" exposure to poll reporting. We define "incidental" reporting on polls in a canton as poll coverage in newspapers that are read in the canton, but whose largest market is elsewhere. If newspaper editors target their news coverage (specifically poll coverage) toward their largest cantonal audience, then readers exposed to this reporting in other cantons will read it for reasons other than their own canton's election-specific interest. We find that greater exposure to this "incidental" reporting on close polls is associated with greater turnout as well.

We close the paper by illustrating the importance of polls and poll coverage for determining election outcomes. We consider two counterfactuals that involve modest deviations from the status-quo information voters possess about election closeness. First, we consider a case in which a second national poll is added to the one poll currently conducted in Switzerland. We assume that individuals consume information aligned with their political positions, in which case supporters of the losing side in a poll would see poll results that are closer than the actual poll results. We find that when supporters of the losing side observe a one standard deviation closer poll result than the actual poll (while supporters of the leading side observe the actual poll), the increased turnout among the "losers" would have flipped the results of two Swiss referenda in our sample. In a second exercise, we counterfactually vary newspapers' coverage of the actual national poll. We consider a scenario in which a newspaper with readers supporting the losing side in a referendum increased coverage of the actual poll to the sample maximum level of coverage (for example, to stimulate readers' turnout). Such a strategy in a single canton would have flipped one referendum. A more systematic effort by the press - increased coverage in ten of Switzerland's twenty-six cantons - would have flipped the results of five referenda.

Our evidence of a causal effect of anticipated election closeness contributes to a growing empirical literature studying the determinants of voter turnout. Existing work has tested rational choice models of voter turnout structurally (e.g., Coate and Conlin, 2004 and Coate et al., 2008) and in the lab (e.g., Levine and Palfrey, 2007, Duffy and Tavits, 2008, and Agranov et al., 2018), finding mixed results. It has also identified other drivers of voter turnout: expressive motives (Pons and Tricaud, 2018), personality traits (Ortoleva and Snowberg, 2015), habits (Fujiwara et al., 2016), social considerations (Gerber et al., 2016, Funk, 2010, and DellaVigna et al., 2016), political movements (Madestam et al., 2013), media content (Strömberg, 2004, Gentzkow, 2006, DellaVigna and Kaplan, 2007, Enikolopov et al., 2011, Gentzkow et al., 2011, and Spenkuch and Toniatti, 2018), the existence of exit poll results (Morton et al., 2015), and compulsory voting laws (León, 2017 and Hoffman et al., 2017). ${ }^{6}$ Our evidence of a causal effect of anticipated election closeness

\footnotetext{
${ }^{6}$ Additional empirical evidence exists on factors affecting other political behaviors, such as contributing to a political
} 
complements this empirical literature and provides support for theoretical models in which voter turnout increases with beliefs about closeness. The counterfactual analysis suggests that institutions shaping these beliefs - particularly polls and media coverage of them - can play a critical role in shaping voter turnout and the outcomes of close elections.

In what follows, in Section 2, we discuss the institutional context of Swiss referenda and in Section 3, we describe our data. In Section 4, we discuss the challenge of identifying a causal effect of anticipated election closeness and present our conceptual framework. In Section 5, we present our empirical results from Geneva, from municipality-level data, and from canton-level data. In Section 6, we conduct our counterfactual analyses of Swiss referenda outcomes. Finally, in Section 7, we offer concluding thoughts.

\section{Institutional Context}

\subsection{Swiss Direct Democracy: Overview and the Issues}

Switzerland is a federal republic consisting of 26 cantons and 2,202 municipalities (as of 2020). Along with a distinct federal structure, Switzerland has a long tradition of direct democracy, practiced at all three levels: federal, cantonal, and municipal. ${ }^{7}$ The two main instruments of direct democracy at the federal level (the level on which we focus) are the popular initiative and the referendum.

Since 1891, Swiss citizens have had the right to call for a popular initiative, with which they can revise the federal constitution, if 100,000 signatures are collected in support of the proposed initiative within 18 months. A popular initiative is accepted if the majority of Swiss citizens vote in favor, and the majority of the cantons do so as well. ${ }^{8}$ In response to an initiative, the Federal Council and the Federal Assembly may propose a direct counter-proposal; usually, this is a more "moderate" proposal. ${ }^{9}$

campaign or turning out to a protest. These range from traditional and social media (Enikolopov and Petrova, 2015, Enikolopov et al., 2020, Durante et al., 2019), to the behavior of other citizens (Perez-Truglia and Cruces, 2017, González, 2020, and Cantoni et al., 2019).

${ }^{7}$ See https://www.ch.ch/en/demokratie/political-rights/, last accessed July 26, 2020, for basic information on Swiss direct democratic institutions at the federal level. More detailed discussion of direct democracy in Switzerland can be found in Linder (2010).

${ }^{8}$ Technically, there are 20 cantons, each of which receives a vote, and 6 half cantons (Obwalden, Nidwalden, BaselStadt, Basel-Landschaft, Appenzell Ausserrhoden and Appenzell Innerrhoden), each of which receives half a vote, making 23 votes in total. In nearly every case in our data, popular and cantonal majorities go hand in hand. Between 1981 and 2019, there were four votes (out of 331) in which a narrow majority of voters approved (between $50.9 \%$ and $54.3 \%$ of voters voting yes) but the cantons did not, and two votes in which a narrow majority of voters rejected (with $49.2 \%$ and $49.9 \%$ of voters voting yes) while the majority of cantons approved. Note that there is no minimum voter turnout required for the referendum to be binding.

${ }^{9}$ In the case of a counter-proposal, voters are currently able to approve both the initiative and the counter proposal, if both are preferred to the status quo (before 1998, voters could only approve the initiative or the counter-proposal, but not both at the same time). Voters who support both the initiative and the counter-proposal are required to indicate which they prefer to determine which is to be implemented if both initiative and counter-proposal were approved. 
In addition to the popular initiative (and the counter-proposal), the Swiss constitution grants two types of referenda rights. First, a referendum can be called on all laws issued by the federal government if supported by 50,000 signatures or eight Swiss cantons. This sort of referendum is then accepted or rejected by a simple majority of the votes cast. Higher-stakes policy choices any changes to the constitution and some international treaties - are subject to a mandatory referendum requiring a majority of voters and cantons to be passed. Swiss citizens vote on federal ballots two to four times per year, with each "election day" including votes on multiple proposals. Vote topics vary broadly, from social issues, to military policy, to infrastructure, to participation in international organizations, such as the European Union. Between 1981 and 2019, Swiss citizens voted on 331 federal ballots, and these ballots were held on 115 election days.

Given the high stakes involved, it is unsurprising that referenda are politically contentious. Political parties regularly take positions and issue voting recommendations. In the 331 votes between 1981 and 2019, the moderate right-wing party (FDP) provided a recommendation on how to vote in all but one vote; the centrist party (CVP) and the populist right-wing party (SVP) provided recommendations in all but three votes; and the major left-wing party (SP) provided a recommendation in all but 17 votes. ${ }^{10}$ The left and the right typically provided voters with contrasting recommendations: there was disagreement among parties in 271 out of 331 of the votes held between 1981 and 2019.

\subsection{The Voting Process and Voter Information}

While the Swiss are asked to vote on many issues, it is important to note that the voting process in Switzerland is quite convenient. No registration to vote is necessary, and every eligible voter (i.e., Swiss citizen of at least 18 years of age) receives the voting documents by regular mail at home. The voter then casts the ballot either at the polling booth on the election day (always a Sunday) or through early voting. Early voting in the last two decades was done primarily via standard mail, but in recent years also online, and could also be done by bringing a ballot personally to the closest electoral office (usually in the municipality where voters live). ${ }^{11}$

Swiss voters are also provided with substantial amounts of information on the substance of the issues on which they will vote. The voting documents sent to eligible voters' homes include the precise questions, arguments for and against each proposition, and often outside opinions from interest groups. In addition, most federal votes are extensively debated in the media (TV, radio and dozens of local newspapers). Political advertising exists, but only in newspapers, with political TV and radio ads prohibited under federal law. ${ }^{12}$

\footnotetext{
${ }^{10}$ See https://swissvotes.ch/page/dataset, last accessed July 26, 2020.

${ }^{11}$ In our sample of Genevan voters, virtually all voters make use of early voting: $90.0 \%$ of those turning out use postal voting and $4.3 \%$ use voting by internet; only $5.7 \%$ cast their vote at the polling booth on Sunday morning. See Funk (2010) for additional institutional information and for a discussion of the different turnout effects of the introduction of voting by mail.

${ }^{12}$ See https : //www . admin.ch/opc/en/classified-compilation/20001794/index.html, last accessed July 26, 2020.
} 


\subsection{The Collection and Dissemination of National Polls}

A pivotal event altering the political media landscape — and voters' information sets - occurred in 1998, when the Swiss public television station decided to sponsor the first widely-disseminated national voting forecasts in Switzerland. The idea was simply to collect politically relevant information to make political discussions on TV more lively, but the poll results ended up being disseminated far more broadly, through other media as well. Pre-election polls were conducted for nearly all votes since June 1998, with a research institute called "gfs.bern" (or " $g f s^{\prime \prime}$ ), responsible for almost all of these.

Two rounds of polls are typically conducted: results of the first poll are published around 5 weeks before the voting Sunday - before any voting can take place - and results of the last poll typically released 11 days before the voting date, the Wednesday in the week prior to the election date. Because our event study analysis of Geneva voter turnout relies on the exact date of the release of the final poll, we note here that of the 52 votes examined in our analysis of Geneva voter turnout, 2 polls were released 16 days before the voting date, 1 poll 13 days before, 2 polls 12 days before, 44 polls 11 days before, and 3 polls 10 days before.

The release of this national-level poll (and its closeness) before each vote provides the key source of variation we will exploit in our event-study analysis of Geneva voters' turnout. In our analysis of the effects of close polls depending on municipality representativeness, we will compare voter turnout before and after 1998, when polling began. And, in our analysis of the role of newspaper dissemination of poll results, we will examine newspaper articles reporting on these national polls. ${ }^{13}$

\section{Data and Summary Statistics}

\subsection{Voter Turnout and Vote Outcomes}

Data on daily voter turnout in the canton of Geneva are obtained from the office of statistics of the canton of Geneva. ${ }^{14}$ To the best of our knowledge, Geneva is the only canton keeping detailed administrative records on the timing of voter turnout. Beginning from the 2-3 weeks before election Sunday (this has varied across election days), the cantonal Service of Popular Votes and Elections registers the number of incoming ballots from early voters at a daily level. The Service of Popular Votes and Elections registers incoming postal ballots - around 90\% of the votes cast in our sample - on working days (including election Sunday and the preceding Saturday, but excluding all

\footnotetext{
${ }^{13}$ To the extent that exposure to information regarding polls via newspapers is a noisy indicator of exposure to information regarding polls by any means, our estimates of the effects of newspaper coverage of polls might be biased. For example, uniform exposure to TV coverage of polls across space would tend to produce an underestimate of the effect of newspaper coverage, while non-uniform exposure to polls (on TV or radio) correlated with newspaper coverage across space would tend to produce an overestimate.

${ }^{14}$ See https://www.ge.ch/statistique/, last accessed on July 26, 2020. Geneva is the 6th largest of Switzerland's cantons, with a population of around 500,000.
} 
other weekends and public holidays). ${ }^{15}$

It is important to note that we do not observe different turnout for each individual vote (i.e., ballot issue) that is decided on the same election day, as the ballots are placed together in a sealed envelope. ${ }^{16}$ There are 52 election days in Geneva for which turnout is observed both before and after the release of pre-election poll results. We thus construct a panel of daily turnout for the voting days preceding these 52 election days. We consider cumulative turnout rate as of each day; the log of the daily count of ballots received; the daily turnout rate as a fraction of the eligible voting population in the canton, and the daily "net" turnout rate, calculated as the turnout rate among the eligible voters who have not yet voted in a particular election.

We additionally consider data on voter turnout and referenda outcomes for all of Switzerland. These data are available for single votes on an election day (i.e., specific ballot issues), disaggregated at the municipal, canton, or federal level, and are provided by the Swiss federal office of statistics. ${ }^{17}$ In our analysis, we use data on: eligible voters, votes cast, the number of votes in support of the initiative, and the number of votes against the initiative. ${ }^{18}$ We calculate an $e x$ post vote closeness measure, which is the share of the votes cast for the losing side in a vote. In our municipality $\times$ vote-level analysis, we use ex post closeness to construct a measure of a municipality's "political unrepresentativeness" prior to the release of any polls: the opposite of the correlation between each municipality's vote share closeness and the national closeness between 1981 and 1998. We also use the measure to calculate a municipality's homogeneity: how much a municipality's voting outcomes differed from 50-50, on average, prior to the release of any polls.

\subsection{Importance of a Vote}

While each election day typically features several votes (ballot issues), we find it plausible that a voter's decision to turn out on the margin will be based on the "most important" vote held on that day. To determine the most important vote on a given election day, we combine data

\footnotetext{
${ }^{15}$ The relatively small number of ballots submitted by internet (around 6\%) are recorded automatically every day (including weekends and public holidays) by the e-voting system. We therefore aggregate votes on eligible "voting days," i.e. days when postal ballots are registered, to which we add any incoming ballots by internet recorded on weekends or public holidays immediately preceding the voting day.

${ }^{16}$ The sealed envelope is then mailed, in a larger envelope, together with the signed voter identification card. To preserve the secrecy of the ballot, authorities are not allowed to open the sealed envelope or to count votes before election Sunday, but only to register the voter identification card.

${ }^{17}$ These data are available for referenda held since 1981. See https://www.pxweb.bfs.admin.ch/pxweb/de/, last accessed July 26, 2020. The municipality-level voting data of the federal office of statistics includes 2,202 municipalities that existed at the end of our sample period, where historical municipalities that merged are aggregated to the set of municipalities in existence at the beginning of 2020. For 19 municipalities, the federal office of statistics reports incomplete data because these municipalities were subject to complex mergers not allowing the aggregation of data by adding up historical electoral returns from formerly independent municipalities. For another 7 municipalities, no data are reported because they share a common ballot box with neighboring municipalities to which electoral returns are aggregated. This leaves us with 2,176 municipalities in our data.

${ }^{18}$ Turnout is calculated at the level of the individual vote. In practice, turnout is very similar for all votes held on a given election day: a regression of turnout on election day fixed effects generates residuals with a standard deviation of 0.128 percentage points.
} 
from several sources. In our analysis of daily voter turnout in Geneva, we use responses in postelection surveys: the "VOX surveys" before September 2016, and the "VOTO Surveys" after. ${ }^{19}$ We specifically rely on survey respondents' views of the personal importance of each voting issue (or referendum) on a given election day. ${ }^{20}$ We identify the vote with the highest personal importance score as the one whose poll closeness may affect turnout for that election day.

This survey-based measure of a vote's importance is direct, and it covers all 52 votes we study in our analysis of voter turnout in Geneva. However, it provides incomplete coverage of votes in our analysis of municipality $\times$ vote and canton $\times$ vote level turnout. In our analysis of municipality $\times$ vote-level turnout, we wish to study voting in the era prior to the release of polls going back to 1981, before survey data on the importance of each voting issue were collected. We thus supplement the VOX and VOTO survey data with a count of the number of articles mentioning each vote (issue) in Switzerland's preeminent German newspaper, the NZZ, in the three months preceding each election day. ${ }^{21}$ In the absence of survey data, the issue with the most NZZ articles is identified as the most important vote on a given election day. In our canton $\times$ vote-level analysis, we are able to include one more election day by shifting to a slightly different survey question from the VOX survey, which asks about the importance of the vote to the nation, rather than about its personal importance. ${ }^{22}$ Table 1 lists a few examples of election days, with the respective issues (votes) on the ballot and their importance scores (Online Appendix Table A.1 lists all the election days and the most important vote on each day).

\subsection{Pre-Election Poll Results}

Since 1998, the Swiss Public TV and Radio Corporation (SRG) has sponsored surveys eliciting the voting intentions of Swiss citizens before all federal votes. We collected poll results, as well as the precise timing of the release of poll results (crucial for our analysis of daily voter turnout in Geneva) from the website of the SRG. ${ }^{23}$ The poll results are reported as the shares of eligible voters (among those who report an intention to vote), who: (i) are definitely in favor of the proposal; (ii) are somewhat in favor of the proposal; (iii) are somewhat against the proposal; (iv) are definitely opposed to the proposal; (v) do not know; or, (vi) prefer not to answer. ${ }^{24}$ Our main variable of

\footnotetext{
${ }^{19}$ The VOX surveys, like the pre-election polls, were conducted by $g f s$. The VOTO surveys were conducted by the research institute FORS. The survey data for both VOX and VOTO can be found at https://forsbase.unil.ch/, last accessed July 26, 2020.

${ }^{20}$ The question reads: "Let's talk about the importance this issue had for you personally. Please tell me ... how important the vote about [issue title] has been for you personally. Tell me a number between 0 and 10. 0 means not important at all, 10 very important."

${ }^{21}$ We checked six major newspapers in Switzerland (NZZ, Blick, Tages Anzeiger, Le Matin, Journal de Genève, and Tribune de Genève) for an available online archive going back to 1981, but only the NZZ had a complete archive throughout this time period.

${ }^{22}$ Our results are nearly identical using the personal importance measure, but we prefer to maximize the sample coverage.

${ }^{23}$ See https: //www. srf.ch/, last accessed July 26, 2020.

${ }^{24}$ Note that the poll does not project whether the referendum is likely to receive support from a majority of cantons (which technically is required to pass many of the referenda we study). As noted above, however, the popular vote has
} 
interest is the predicted closeness of the final poll prior to a vote. To calculate poll closeness we first construct the "share yes": the total "yes" support (groups (i) and (ii), who are definitely or somewhat in favor) divided by the total number of respondents indicating support for "yes" or "no" (groups (i), (ii), (iii), and (iv)). We then analogously construct the "share no," and code ex ante poll closeness as the vote share of the losing side. Our empirical ex ante (i.e., poll) closeness measure will be the vote share of the losing side in the poll.

\subsection{Data on Newspaper Coverage of Polls}

The Swiss Agency of Media Research (WEMF) has regularly conducted surveys on newspaper readership since the year 2000, with random samples of cantonal inhabitants interviewed and asked which newspapers they read. ${ }^{25}$ The Agency generously shared their data on canton-level newspaper readership with us, allowing us to construct a list of newspapers read by at least $10 \%$ of a canton's inhabitants in a given year. Overall, there are 50 newspapers on this list, many of which are read in several cantons (see Online Appendix Table A.2, for a list of the newspapers). To measure canton-level coverage of pre-election polls, we count the number of times a pre-election poll was mentioned in each of the newspapers read by at least $10 \%$ of a canton's inhabitants, between 2000 and 2014. We used three different strategies in this search: online databases, "Factiva" and "Swissdox"26; newspapers" own online archives; and, manual search in the Swiss National Library in Bern.

In our empirical analysis below, we will address concerns regarding the endogenous local newspaper coverage of close polls by exploiting a canton's voters' (arguably) "incidental" exposure to polls. We propose that newspaper editors may target their news coverage (specifically, poll coverage) toward their largest cantonal audience; if so, then readers exposed to this reporting in other cantons will read it for reasons other than their own canton's election-specific interest. We thus can decompose total coverage of polls in a canton into two components: first, endogenous coverage, which is arguably targeted toward that canton, because it represents a newspaper's largest cantonal audience; second, incidental coverage, to which a canton is exposed despite a newspaper's largest audience being in a different canton. We use the newspaper readership data to define incidental poll exposure in two ways: first, coverage by a source with a majority readership in a different canton; second, and more conservatively, coverage by a source with at least $85 \%$ readership in other cantons (Online Appendix Figure A.2, shows how endogenous and incidental coverage vary by canton).

nearly always been the binding factor determining the passage of referendum; thus, information on the closeness of this component of the vote alone will be highly informative to voters.

${ }^{25}$ See https : //wemf .ch/, last accessed July 26, 2020.

26 See https://global.factiva.com and https://swissdox.ch/, both last accessed July 26, 2020. 


\subsection{The Political "Supply Side": Political Advertising in Newspapers}

For our analysis of voter turnout in the canton of Geneva, we hand-collected all political advertisements related to the 52 referenda studied between 2001 and 2019 for the two most widely-read Genevan newspapers: Le Temps and Tribune de Genève. We aggregate these data to counts of political ads relating to each of the 52 votes at the daily level.

For our analysis of voter turnout across Switzerland, we measure political advertising using data from Kriesi (2009) and the Année Politique Suisse on political ads in six major Swiss newspapers: NZZ, Blick, Tages-Anzeiger, Le Matin, Journal de Genève, and Tribune de Genève. ${ }^{27}$ To measure campaigning intensity at the vote level, we calculate the sum of ads placed in these six major newspapers relating to each vote.

For our canton $\times$ vote-level analysis, we collected advertising data from a much broader set of newspapers: all of the newspapers read by at least $10 \%$ of any canton's inhabitants. We sum up to the canton $\times$ vote level our counts of political ads relating to each vote for each newspaper read in each canton.

\subsection{Summary Statistics}

We present summary statistics for the datasets used in our empirical analysis in Table 2. First, we consider our primary dataset of interest: vote $\times$ day-level data for the canton of Geneva (Panel A). We observe voting, on days both before and after polls are released (around 15 days per vote) for 52 "most important" votes held on election days since 2001 (757 vote $\times$ day observations in total). Around 3\% of eligible voters vote on an average day; cumulative turnout is around $28 \%$ on the average day (which of course will be higher by the day of the election itself). The average ex ante poll closeness in our sample is 38.30 (that is a 62-38 margin for the winning side). Finally, on the average day in our sample, we count 1.6 newspaper ads related to the upcoming vote in the two major Genevan newspapers. ${ }^{28}$

Second, we turn to the vote-level dataset at the federal level (Panel B). It is composed of the "most important" issue for each of the 115 election days for which we have voter turnout data between 1981 and 2019. On average, over 40\% of eligible voters turn out; the average margin is around $65 \%-35 \%$; voters rate the importance of the issue to themselves as a 6 out of 10 in importance; and, the average vote saw around 100 ads placed in the major Swiss newspapers. ${ }^{29}$

Third, we construct a municipality $\times$ vote-level dataset, including voting data for 2,176 municipalities and 115 "most important" votes held between 1981 and 2019 (Panel C). In addition

\footnotetext{
${ }^{27}$ Hanspeter Kriesi generously shared data for votes from 1981 to 2014, which we supplemented with the Année Politique Suisse for more recent votes (see https ://anneepolitique.swiss/pages/campaign_research, last accessed July 26, 2020).

${ }^{28}$ We are missing ads data for 52 voting days - the election Sunday for each of our votes.

${ }^{29}$ Data on the importance of the vote are missing for 32 votes because the VOX surveys did not include this question before 1993. Missing data for political ads are inherited from the Kriesi (2009) dataset.
} 
to summary statistics that match the vote-level data at the federal level (subject to differences due to the construction of the municipal-level data), one can see that $60 \%$ of the votes in our municipality $\times$ vote-level analysis were held after polls were introduced; the average municipality has an unrepresentativeness value of -0.59 (meaning that the average correlation between national and municipality closeness is around 0.60 ), but this ranges from close to -1 (a nearly perfect correlation between municipality and national closeness) to around 0 (implying no correlation between the municipality closeness and national closeness).

Fourth, we construct a canton $\times$ vote-level dataset, including voting data for 26 cantons and 37 "most important" votes held between 1998 and 2014 (Panel D). This panel is limited to votes for which we have a count of newspaper articles mentioning polls and political ads relating to votes in the 50 newspapers read by at least $10 \%$ of a canton's population. One can see that this slightly smaller sample, relative to the Geneva dataset that also examines the poll era, does not look very different in terms of poll closeness: on average, this is around 38 (i.e., a $38 \%$ share for the losing side) in both samples. We count around 4 newspaper articles mentioning polls for the average vote, with 2.5-3 articles mentioning polls published in newspapers read in a canton, but having a larger market elsewhere (our measure of "incidental" exposure to information). We count, on average, around 70 political advertisements on the most important vote in the newspapers read in a canton. Finally, we note that the personal importance of this set of votes looks very similar to the full sample. ${ }^{30}$

\section{The Identification Challenge, Conceptual Framework, and Hypothe- sis Tests}

Abundant evidence exists of a correlation between election closeness and voter turnout. This correlation can arise from three sources: first, voters may turn out more when they anticipate a close election - this is the causal effect of closeness, working through voter beliefs, that is of interest to us. Second, unobserved issue type may drive both closeness and turnout: for example, more important referenda issues (or election races) may be more contentious (and hence closer) and also motivate voter turnout. Third, the actions of the political supply side, that is, political actors and organizations with a stake in the referendum (election) outcome, may be correlated with both voter turnout and closeness: for example, high levels of political advertising on two sides of an issue would tend to drive up turnout and closeness.

One can see in Figure 1 that in our setting, the closeness of Swiss referendum results is indeed strongly, positively associated with voter turnout (Panel A). But, the importance of an issue (measured in voter surveys) and political advertising are also strongly, positively associated with voter turnout (Panels B and C). And, the importance of an issue and political advertising are strongly,

\footnotetext{
${ }^{30}$ Importance data are missing for five observations because the VOX survey did not receive responses from small cantons for these votes.
} 
positively associated with referendum closeness (Panels D and E) and with each other (Panel F).

The ideal experiment would randomly shock voters' beliefs about election closeness, while holding fixed the issue type and the political supply side. We identify a setting that approximates this experiment: the sharp arrival of information about election closeness in newly-released polls. Using unique data from the canton of Geneva that allow us to observe voter turnout day-by-day, around the day when polls are released, we can test whether the release of closer polls differentially increases voter turnout (accounting for issue fixed effects). Furthermore, we can evaluate whether the natural experiment we study is a good one, by testing for differential turnout levels and trends prior to the release of closer polls — such an effect might arise if closer polls were anticipated; if issue types that were associated with closer polls were also associated with different turnout trends, or if the political supply side were differentially active prior to poll release on issues that (eventually) have closer polls.

To be precise, we estimate the following model:

$$
\text { turnout }_{v d}=\sum_{d} \beta_{d} \text { Close }_{v}+\alpha_{v}+\gamma_{d}+\epsilon_{v d}
$$

This is a simple event study, examining voter turnout by vote $\times$ day, where "day" is the number of days prior to, or following release of a poll. The coefficients of interest are the sequence of $\beta_{d}$, which are estimated as coefficients on the interaction of poll closeness $\left(\mathrm{Close}_{v}\right)$ with a full set of day-to-poll indicators. These tell us how turnout varies in the days before or after a closer poll is released - accounting for vote $(v)$ and day-to-poll $(d)$ fixed effects. Our proposed mechanism of a causal effect of closer polls through changed voter beliefs about closeness suggests that $\beta_{d}$ will be very close to 0 for $d<0$ and significant and positive for some $d>0$.

In addition to examining voter turnout, we can also directly study the political supply side by estimating the event study model in equation (1), but predicting political ads by vote $\times$ day. If close polls causally shape turnout, one might expect the political supply side to respond to them as well - albeit likely with some lag given the need to develop ads and place them. Crucially, we predict a response of voter turnout prior to any political supply side response.

After testing for a causal effect of closer polls on voter turnout in Geneva, we then test two sets of auxiliary predictions arising from our proposed mechanism that polls affect turnout by shaping voters' beliefs about election closeness. First, we test for heterogeneous effects of the introduction of polls in Switzerland in 1998. In the absence of information from national, pre-election polls, it is plausible that voters will gauge an upcoming election's closeness by "locally sampling" among their friends and neighbors. This strategy will yield beliefs that reflect the actual national-level closeness only if the local sample is politically representative of the country as a whole. In such cases, it may be possible to condition the turnout decision on an informative local signal even in the absence of national polls. In contrast, in politically unrepresentative municipalities, it will 
not be easy for individuals to condition their turnout decision on national-level vote closeness. ${ }^{31}$ Once polls are introduced, however, voters in both politically representative and politically unrepresentative municipalities will be able to condition their turnout on an accurate signal of election closeness.

Our hypothesis of local sampling should produce several patterns in the data. Under the assumption that voters turn out more when they anticipate a closer election, and that they condition their turnout decisions on national-level poll results (rather than local information) when available, we should observe: (i) in the era before polls, the closeness-turnout relationship should be positive in more politically representative municipalities, but there should be no relationship in politically unrepresentative municipalities. In other words, there should be a significant difference in the closeness-turnout gradient between politically representative and politically unrepresentative municipalities in the era without polls. (ii) The introduction of polls should have a significantly larger effect on the closeness-turnout relationship in politically unrepresentative municipalities (the poll has a larger effect on voters' information sets there). (iii) There should be convergence toward the same closeness-turnout relationship in the era with polls: i.e., no difference in the closeness-turnout gradient in the era with polls.

We test these predictions using a municipality $\times$ vote panel, pooling data from the era with and without polls (and thus using an ex post measure of election closeness), and estimating the following model:

$$
\begin{aligned}
\text { turnout }_{m v}= & \alpha_{m}+\gamma_{v}+\delta_{1} \text { closeness }_{v} \times \text { unrepresentative }_{m} \times \text { PollEra }_{v} \\
& +\delta_{2} \text { closeness }_{v} \times \text { unrepresentative }_{m} \\
& +\delta_{3} \text { unrepresentative }_{m} \times \text { PollEra }_{v}+\varepsilon_{m v} .
\end{aligned}
$$

It is useful to match our conceptual framework's hypotheses to regression coefficients. Prediction (i) suggests a significant and negative coefficient $\delta_{2}$. Prediction (ii) implies a positive and significant coefficient $\delta_{1}$. Prediction (iii) suggests that the sum of the coefficients $\delta_{1}+\delta_{2}$ will be insignificantly different from zero.

Our second set of auxiliary predictions regards heterogeneity in the dissemination of information about election closeness. Quite simply, in locations where individuals read newspapers that report more on poll results, the impact of poll closeness should be magnified. Using our canton $\times$ vote panel data, we test whether there exists a differential positive relationship between ex ante poll closeness and turnout in cantons with greater reporting on polls in local newspapers, controlling for vote fixed effects - and thus a national-level "issue type" — as well as canton fixed

\footnotetext{
${ }^{31}$ Voters in politically unrepresentative municipalities may turn out more in response to local signals of closeness, but because these signals are uncorrelated with national-level closeness, they will not turn out systematically more for (nationally) closer elections. It is also possible that because their local signals are uninformative, they choose not to act on them.
} 
effects. We estimate the following model:

$$
\text { turnout }_{c v}=\phi_{c}+\mu_{v}+\psi_{1} \text { closeness }_{v} \times \text { coverage }_{c v}+\psi_{2} \text { coverage }_{c v}+u_{c v},
$$

where turnout $_{c v}$ is the turnout rate (in percent) in canton $c$ for vote $v, \phi_{c}$ are a set of canton fixed effects, and $\mu_{v}$ are a set of vote fixed effects. The interaction closeness $_{v} \times$ coverage $_{c v}$ is the explanatory variable of interest, with the coefficient $\psi_{1}$ telling us whether close polls have a differential impact on turnout specifically when they are covered more by a canton's newspapers. ${ }^{32}$

To account for endogenous targeting of news - editors may choose to report on polls in response to their readers' preferences - we exploit a canton's voters' (arguably) "incidental" exposure to polls. If newspaper editors target their news coverage (specifically, poll coverage) toward their largest cantonal audience, then readers exposed to this reporting in other cantons will read it for reasons other than their own canton's election-specific interest. We thus can decompose total coverage of polls in a canton into two components: first, endogenous coverage, which is arguably targeted toward that canton, because it represents a newspaper's largest cantonal audience; second, incidental coverage, to which a canton is exposed despite a newspaper's largest audience being in a different canton. We test whether greater incidental coverage of close polls also increases turnout.

\section{Empirical Analysis}

\subsection{Event-Study Evidence from the Canton of Geneva}

Our analysis of voter turnout in Geneva examines whether, in the days following the release of closer polls, voters turn out more. In Figure 2, we present prima facie evidence that close polls increase turnout, showing (raw) cumulative voter turnout (Panel A) and net voter turnout rates (Panel B) day by day around the time when polls are released, and splitting polls into above- or below-median closeness (above or below a $40 \%$ vote share for the losing side). One can see that voter turnout follows a very similar pattern day by day up to poll release for votes that would eventually have closer or less close polls. But, once polls are released, voter turnout diverges sharply, particularly in the three days immediately following poll release.

We next more formally test for the effect of closer polls. We estimate the event study equation (1) presented above, examining the effects of closer polls on net voter turnout rates day by day. One can see in Figure 3 coefficient estimates (and 95\% confidence intervals) on the interaction of (standardized) poll closeness with each day-to-poll indicator (with the day of poll release the omitted reference day). ${ }^{33}$ Prior to the day when polls are released, we see no difference in turnout rates depending on the closeness of the to-be-released poll. In contrast, on the first three days af-

\footnotetext{
${ }^{32}$ Note that the lower-order term closeness $_{v}$ is omitted as it is collinear with the vote fixed effects.

${ }^{33}$ The coefficient estimates and standard errors are also presented in Online Appendix Table A.3, column 1.
} 
ter a closer poll is released, voter turnout rates are significantly higher — by around 0.4 percentage points. ${ }^{34}$ This is not merely vote shifting across time, as coefficient estimates remain above 0 up through election day (consistent with the higher cumulative turnout for votes with closer polls seen in Figure 2).

We present several robustness exercises in Figure $4 .{ }^{35}$ First, in Panel A, we pool net voter turnout into two-day bins, which increases the precision of the estimated time-varying effect of closer polls, and confirms our baseline results. In Panel B, we adjust the denominator of the voter turnout rate, using the fixed eligible number of voters, rather than accounting for the individuals who already voted on prior days; our results are qualitatively unchanged (though estimated effects on days beyond one day following poll release are smaller, given the turnout effect on that first day). In Panel C, we present estimates from a balanced panel, limiting the window to 2 days prior to poll release through election day, as some votes do not have voting data for earlier days. One can see that our results are not sensitive to this choice of sample window. Finally, in Panel D, we examine the log of the daily turnout level as the outcome, and again our results are unaffected.

The results presented in Figures 3 and 4 provide evidence of a causal effect of anticipated closeness on voter turnout. Higher turnout just after the release of close polls is not driven by issue type: time-invariant issue type that might be associated with voter turnout is accounted for by the vote fixed effects; day-varying effects of issue type on voter turnout are ruled out by the insignificant differences in voter turnout rates observed for all of the days prior to the release of closer polls.

Nor can the political supply side account for the response of voter turnout to the release of closer polls. The absence of pre-trends suggests that the supply side was not differentially active prior to the release of close polls; poll results do not seem to have been anticipated. However, the release of polls may affect the supply side directly (if this information about closeness was not available to campaigns before) or indirectly (e.g., because anticipated greater voter turnout in closer votes increases the returns to persuasion through ads).

We thus estimate our event study model (equation (1)), but now examining the effects of closer polls on political advertisements day by day, both before and after poll release. The results are reported in Figure 5. As in Figure 3, we find no difference in political behavior (in this case advertisements) depending on the closeness of the to-be-released poll prior to poll release. After the release of closer polls, we continue to see no effect of closer polls on ads until three days after the

\footnotetext{
${ }^{34}$ It is worth clarifying how polls released on day $t$ can produce an increase in votes counted on day $t+1$. This can arise through several mechanisms: first, when poll result are released on the morning of day $t$, voters may respond by mailing a ballot in time for the vote to be counted on day $t+1$. Second, even when polls are released on the evening of day $t$, voters are able to hand-deliver their ballots to the electoral office on day $t+1$ or to vote online on day $t$ or day $t+1$.

${ }^{35}$ Coefficient estimates and standard errors are provided in Online Appendix Tables A.3 and A.4. In those tables, we also estimate models including fixed effects for each day-to-election (not perfectly collinear with day-to-poll because the poll release day is not always the same number of voting days prior to the election). These fixed effects have no impact on our results. Note that day-to-election fixed effects also account for differences in turnout by days of the week, which are perfectly collinear with day-to-election fixed effects (because election day is always a Sunday).
} 
poll, when we observe significantly more ads in response to a closer poll. This suggests that there is some supply side response to closer polls, but that it appears with a lag. It also suggests that endogenous changes in the behavior of the political supply side cannot account for all of the voter turnout effect that we observe in response to closer polls: political ads printed three days after the release of a poll would generally affect votes counted four or more days after poll release. Yet we find the largest effects of close polls on votes counted in the first three days after poll release.

Our results thus suggest that polls causally affect voters' turnout by providing them with information about upcoming election closeness, which affects voters' beliefs and thus turnout. We next test auxiliary predictions of this proposed mechanism.

\subsection{Heterogeneous Effects of Polls depending on Municipality Representativeness}

We first test a set of hypotheses regarding the effects of the introduction of polls in Switzerland in 1998. We propose that the availability of information about the national-level closeness of an upcoming vote will be particularly valuable — and differentially affect voter turnout — in municipalities that are politically unrepresentative of Switzerland, where local signals of election closeness are unreliable. ${ }^{36}$ We begin by providing the raw correlation between election closeness and municipality voter turnout, splitting the sample of municipalities above and below the median level of political unrepresentativeness in our sample, and examining separately the set of votes held before polls were conducted and the set of votes with polls.

In Figure 6, one can see patterns matching our predictions: in the absence of polls, among relatively unrepresentative municipalities, there is practically no relationship between election closeness and turnout. Among more representative municipalities, there is a stronger positive gradient - the difference in slopes between the representative and unrepresentative municipalities is statistically significant ( $p=0.01$ ). In contrast, in there era when polls are conducted, there is no difference between unrepresentative and representative municipalities in their relationship between election closeness and voter turnout ( $p=0.693$ ). In both sets of municipalities the slope is positive and significant $(p<0.01)$ and the difference in differences (comparing the eras with and without polls) is statistically significant as well ( $p=0.037)$. Finally, the magnitudes are substantial: a one-standard deviation closer election is associated with around 2.5 percentage points higher turnout when polls are released. In the absence of polls, a one-standard deviation closer election was associated with around 1.7 percentage points higher turnout in municipalities that were representative of Switzerland, and only 0.7 percentage points in municipalities that were unrepresentative.

In Table 3, column 1, we provide regression estimates of equation (2), examining the relationship between election closeness and municipality voter turnout depending on municipality

\footnotetext{
${ }^{36}$ As a reminder, "unrepresentativeness" is calculated as the opposite of the correlation between each municipality's vote share closeness and the national closeness between 1981 and 1998 (prior to the release of any polls). See Online Appendix Figure A.3, Panel A for the distribution of unrepresentativeness.
} 
unrepresentativeness and on the existence of polls, accounting for vote and municipality fixed effects. We find estimates that confirm the predictions made in Section 4: (i) there exists a significant difference between representative and unrepresentative municipalities in the relationship between election closeness and turnout in the era without polls (the coefficient on closeness $_{v} \times$ unrepresentative $_{m}$ is negative and statistically significant). (ii) The effect of the release of polls on the relationship between election closeness and turnout is greater in unrepresentative municipalities (the coefficient on closeness $_{v} \times$ unrepresentative $_{m} \times$ PollEra $_{v}$ is positive and statistically significant). (iii) With polls available, there no longer is a significant difference between representative and unrepresentative municipalities in their relationship between election closeness and turnout: We cannot reject that the sum of the coefficients on closeness $_{v} \times$ unrepresentative $_{m}$ and closeness $_{v} \times$ unrepresentative $_{m} \times$ PollEra $_{v}$ equals $0, p=0.798$.

One might wonder whether unrepresentative municipalities are simply smaller than representative ones, with municipality size driving the patterns observed (unrepresentativeness is negatively correlated with electorate size, $r=-0.15$ ). To account for the effects of municipality size, we control for the triple interaction among closeness, municipality electorate size, and a Poll Era dummy ( closeness $_{v} \times$ electorate $_{m} \times$ PollEra $_{v}$ ) as well as all of the lower-order terms. One can see in Table 3, column 2, that accounting for differences in the size of municipalities does not affect our results.

Finally, one might wonder what are some of the underlying local political characteristics that may generate unrepresentativeness? We propose that one plausible source is political homogeneity: a very homogeneous municipality will likely never have locally close elections, as voters will always skew strongly toward one side. This implies that there will be little or no correlation between local closeness and national closeness. Indeed, we find a strong correlation between municipality political homogeneity and unrepresentativeness $(r=0.60) .{ }^{37}$ In Online Appendix Figure A.4 and Table A.5, we show that the patterns of heterogeneity observed with respect to municipality unrepresentativeness also appear with respect to homogeneity, as we would expect.

\subsection{Heterogeneous Effects of Polls depending on Newspaper Coverage}

We next test whether variation in voters' exposure to information about polls affects voter turnout. To do so, we estimate the canton $\times$ vote-level equation (3) and test for a differential closenessturnout gradient in cantons with greater reporting on polls in local newspapers, controlling for vote fixed effects - and thus a national-level "issue type" - as well as canton fixed effects.

In Table 4, Panel A, column 1, one can see that indeed, voter turnout is significantly greater when ex ante closer polls are reported on more often. We plot the estimated effect of one standard deviation greater poll coverage across levels of (standardized) poll closeness in Figure 7. One can see that a poll that is one standard deviation closer than average (where there is substantial

\footnotetext{
${ }^{37}$ The distribution of political homogeneity is provided in Online Appendix Figure A.3, Panel B.
} 
support in the data) increases voter turnout by a statistically significant 0.5 percentage points when newspaper coverage is one standard deviation greater. At average closeness, more coverage has little effect, and when newspapers report more on polls that are not close, turnout is predicted to be substantially smaller, as one would expect.

Of course, it is possible that greater coverage of close polls in locally-read newspapers is correlated with a canton $\times$ vote-specific unobservable that might shape turnout. We consider several possibilities. First, it is possible that locally-targeted political campaigning is associated with both local newspaper coverage of close polls and turnout. To evaluate this concern, we estimate equation (3), but predicting the number of political ads in a canton's newspapers for a given vote. As can be seen in Table 4, Panel A, column 3, while greater newspaper coverage of polls in general is associated with the number of ads, the differential coverage of closer polls is not associated with political ads. The political supply side thus does not seem to account for our findings.

Another possibility is that newspapers providing more coverage of closer polls may also include other coverage that motivates turnout - for example, by persuading readers that a particular vote is important, in addition to being close. We thus estimate equation (3), but predicting cantonal voters' ex post assessment of an issue's importance. As can be seen in Table 4, Panel A, column 5, we find no evidence of greater perceived importance of an issue when a canton's newspapers cover close polls more. Thus, alternative newspaper content does not seem to drive our results. ${ }^{38}$

Finally, differences across Switzerland's linguistic-cultural communities represent another possible source of variation in both newspaper poll coverage and voter turnout. For example, perhaps newspapers read by German-speaking Swiss are more likely to report on close polls and Germanspeaking Swiss are also more likely to turn out to vote in close elections, but greater coverage may not cause the higher turnout. To account for differences in turnout across linguistic-cultural communities depending on a vote's closeness or on a vote's coverage, we control for interactions between an indicator that a canton is German-speaking with pre-election poll closeness as well as with cantonal poll coverage. Including these controls does not affect our any of our results (Table 4, Panel A, columns 2, 4, and 6).

As an alternative approach to addressing concerns regarding the endogenous local newspaper coverage of close polls, we exploit a canton's voters' arguably "incidental" exposure to polls. As explained in section 3.4 above, we decompose total coverage of polls in a canton into endogenous coverage, by newspapers whose largest audience lies in that canton, and incidental coverage, by newspapers that are read in that canton but whose largest audience lies elsewhere. Incidental coverage of polls in our data is only very weakly correlated with endogenous coverage (the correlation is -0.153). ${ }^{39}$ We thus examine the impact of incidental coverage of pre-election polls at the

\footnotetext{
${ }^{38}$ While we prefer not to control for political ads and vote importance, as they are endogenous with respect to our explanatory variable of interest, we note here that their inclusion in the model presented in Table 4, column 1, does not affect our results.

${ }^{39}$ We present each canton's endogenous and incidental exposure to newspaper coverage of polls in Online Appendix
} 
canton $\times$ vote level, plausibly a "cleaner" source of variation in exposure to information regarding the closeness of an upcoming election. ${ }^{40}$

In Table 4, Panel B, we present estimates from specifications analogous to those in Panel A, but now exploiting within-vote variation in exposure to incidental coverage of pre-election polls. One can see that greater coverage of closer polls continues to predict higher turnout (column 1) and that this effect is robust to including controls for interactions between an indicator that a canton is German-speaking with pre-election poll closeness as well as with cantonal poll coverage (column 2). The coefficient on the interaction between poll closeness and incidental exposure is about $25 \%$ smaller than the coefficient in Panel A, but this does not necessarily imply that the coefficient in Panel A was biased: our measure of incidental poll coverage necessarily excludes coverage of polls in widely-read newspapers, which would plausibly have large effects on turnout. One continues to see no relationship between greater coverage of closer polls and political advertisements or voters' perceptions of issues' importance (columns 3-6). In Panel C, we repeat the same exercises, but now implementing a more demanding measure of "incidental" newspaper coverage of polls, requiring that a canton represent less than $15 \%$ of a newspaper's readership. Our findings are much the same as in Panels A and B: greater coverage of closer polls is associated with significantly higher voter turnout; this does not seem to be driven by different cultural/linguistic groups; and it does not seem to be driven by political ads or changes in voters' perceptions of vote importance. $^{41}$

\section{Counterfactuals}

Does our identified effect of anticipated election closeness on voter turnout affect election outcomes in a substantial way? To shed some light on this question, we consider two counterfactual exercises that represent modest deviations from the status-quo set of information about election closeness possessed by voters. ${ }^{42}$ We find that the effects of anticipated closeness on turnout are large enough to flip several high-stakes referenda outcomes in these counterfactuals, on issues

${ }^{40}$ Of course, it is possible that a newspaper's readers will have correlated political preferences across cantons, which shape turnout; these analyses are thus best viewed as suggestive.

${ }^{41}$ As a final exercise with the canton $\times$ vote data, we use incidental exposure to poll coverage as an instrument for total exposure (and the interaction between poll closeness and incidental newspaper coverage of polls as an instrument for the interaction between poll closeness and total newspaper coverage of polls). In Online Appendix Table A.6, one can see: (i) strong first stage estimates; (ii) the coefficient on incidental articles on polls in the first stage predicting total articles on polls is not greater than 1, suggesting that an additional incidental article is not associated with more endogenous articles (the p-value from a one-sided test is $<0.001$ ); and (iii) the IV estimate (using the empirical specification from Table 4, column 1) is somewhat larger than the OLS. This suggests that endogenous coverage of close polls may be greater when turnout is lower for other reasons: for example, newspaper editors may wish to stimulate turnout when they believe turnout will be lower than they think it ought to be.

${ }^{42}$ Note that we do not consider simply replacing the actual poll results with counterfactual results. This would have no impact on vote shares as long as anticipated closeness does not differentially affect the turnout decision of voters with different preferences.
} 
including corporate taxation, military policy, asylum for refugees, and immigration.

In our first exercise, we consider a case in which a second national poll is added to the one poll currently conducted in Switzerland. We assume that this second poll is one standard deviation closer than the actual poll (capped at maximal closeness of 50-50) and that individuals consume information aligned with their own political positions, perhaps because newspapers systematically report on poll results that are skewed toward their readers' political preferences. In this case, supporters of the leading side in a poll would see the actual poll results, while supporters of the losing side in a poll would see results that are closer than the actual poll results.

To calculate the increased turnout in response to the closer poll, we first estimate a simple OLS regression of federal turnout on ex ante (that is, poll) closeness in the sample of 57 most important votes with a pre-election poll. This regression yields a coefficient of $0.16(p<0.1)$ : a one standard deviation (around 7.7 percentage point) closer poll thus increases turnout rates by just over 1 percentage point. ${ }^{43}$ Applying this higher turnout rate to the individuals who support the losing side in a poll, but did not turn out in the actual vote, generates an increase in turnout sufficient to flip two of the votes in our sample (see Table 5, Panel A).

We also consider the reverse case: i.e., the possibility that the second poll is less close than the actual poll, and that this less close poll informs supporters of the leading side in the poll. As a result, turnout by the leading side is reduced, and two of the votes in our sample are flipped as well (see Table 5, Panel B).

In our second exercise, we consider the variation in newspapers' coverage of the actual national poll, whose effects are analyzed in section 5.3 above. We consider a scenario in which newspapers with readers supporting the losing side in a referendum increase their coverage of the actual poll such that the supporters of the losing side of the vote in a particular canton are exposed to the sample maximum level of cantonal newspapers' poll coverage. To calculate the increased turnout in response to greater poll coverage, we apply the estimated effects of greater poll coverage from our canton $\times$ vote-level analysis (Table 4, Panel A, column 1 ) to the individuals who support the losing side in a poll, but did not turn out in the actual vote.

We conduct this exercise one canton at a time, and find that such increased poll coverage (directed toward the losing side in a vote) in a single canton would have flipped one referendum among the thirty-seven we consider. A more systematic effort by the press - increased coverage in more cantons - would flip additional referenda, with increased coverage in ten of Switzerland's twenty-six cantons reversing the results of five of thirty-seven referenda (see Table 5, Panel C).

Our two counterfactual exercises thus suggest that the effect of anticipated election closeness on voter turnout is large enough to be policy relevant. It is strong enough that policies restrict-

\footnotetext{
${ }^{43}$ To estimate this national-level counterfactual, we prefer to use a parameter estimate derived from national-level outcomes ( 57 votes, rather than the 52 votes available in the Geneva data). We note however that this estimate is quantitatively very similar to the turnout effect identified in the Geneva sample, following the release of a closer poll.
} 
ing the number of polls conducted or regulating their dissemination can meaningfully affect the composition of the electorate and high-stakes public policy outcomes.

\section{Conclusion}

Our finding of a causal effect of anticipated election closeness on voter turnout provides empirical support for a key reduced form prediction made by a range of models of voter turnout. By isolating the effect of information about election closeness from unobserved issue type and the behavior of the political supply side, it contributes a crucial existence result to a vast empirical literature that had lacked a well-identified effect of closeness on turnout.

Yet, much work remains to be done. One naturally wonders about the external validity of our existence result: how general is the causal effect of election closeness on turnout? While the context we study has distinctive features - we study voter turnout for referenda, rather than traditional elections, in a country with a long democratic tradition — we believe it likely generalizes to a range of important settings. First, referenda play a role around the world in deciding high-stakes issues: from Brexit, to the decision to end the Pinochet regime, to many important policy issues in the state of California (which looks like the Swiss case, with many referenda voted on each year). More generally, as described in Section 2, Swiss referenda often produce highstakes political competitions between left- and right-wing parties. In this sense, Swiss referenda are single-issue analogues of the majoritarian political competition that exists elsewhere. Still, it remains important to estimate causal effects of anticipated election closeness on voter turnout in other settings. In addition, it is important to examine effects of polls through mechanisms other than anticipated closeness alone: for example, polls may have differential effects on the leading and losing sides (see for example, Rogers and Moore, 2015), a possibility from which we abstract in our study. Finally, one would like to unpack the reduced form effect of election closeness we observe to better understand its theoretical underpinnings, whether considerations of pivotality, or intrinsic or social motives.

Our analysis also has important practical implications. While much research on political behavior has focused on the effects of persuasive information in newspapers, on television, or in advertisements, our findings indicate that information about an election's competitiveness can shape political behavior as well. In a context of increased political polarization (e.g., Boxell et al., 2017), persuasion aimed at changing the ideological preferences of voters may be less effective, making the turnout margin that we study - changing the ideological composition of the voting electorate - potentially more important than in the past.

Though admittedly quite speculative, an application to the 2016 United States Presidential election is illustrative. Political commentators have suggested that low voter turnout played a role in Donald J. Trump's victory. ${ }^{44}$ Interestingly, while media across the political spectrum con-

\footnotetext{
${ }^{44}$ See, e.g., the Washington Post article, "Hillary Clinton's campaign was crippled by voters who stayed home," by
} 
sistently predicted a Clinton victory, in a sample of 5 media outlets, we find that on Election Day, more right-leaning sources, likely read by more right-leaning voters, generally reported lower estimates of the probability of a Clinton victory — that is, a closer election - than did more leftleaning sources (Fox News reported the closest election, with an $80 \%$ chance of a Clinton victory; see Online Appendix Figure A.5). If closer polls motivated greater turnout, variation in polls reported across media outlets may have played some role in shaping turnout and the outcome in the U.S. Presidential Election.

Our analysis thus points to an important policy implication: the regulation of polls' conduct and their dissemination can have important consequences for election outcomes. There is a remarkable degree of variation across countries in such regulation: for example, in Australia and in the United States there is none; in Italy, polls are prohibited within 15 days of a vote; and, in Switzerland, no information on polls can be released in the 10 days before the vote. The impact of these regulations on a range of policy outcomes might be far greater than many policymakers realize.

Philip Bump, dated November 9, 2016. Article available at https://goo.gl/Irfy0c, last accessed July 26, 2020. 


\section{References}

Agranov, Marina, Jacob Goeree, Julian Romero, and Leeat Yariv, "What Makes Voters Turn Out: the Effects of Polls and Beliefs," Journal of European Economic Association, 2018, 16 (3), 825-856.

Ali, S. Nageeb and Charles Lin, "Why People Vote: Ethical Motives and Social Incentives," American Economic Journal: Microeconomics, May 2013, 5 (2), 73-98.

Barzel, Yoram and Eugene Silberberg, "Is the act of voting rational?," Public Choice, September 1973, $16(1), 51-58$.

Bennion, Elizabeth A., "Caught in the Ground Wars: Mobilizing Voters during a Competitive Congressional Campaign," Annals of the American Academy of Political and Social Science, September 2005, 601 (1), 123-141.

Boxell, Levi, Matthew Gentzkow, and Jesse M. Shapiro, "Is the Internet Causing Political Polarization? Evidence from Demographics," NBER Working Paper, March 2017, w23258.

Brennan, Geoffrey and James Buchanan, "Voter Choice: Evaluating Political Alternatives," American Behavioral Scientist, November 1984, 28 (2), 185-201.

Cancela, Joao and Benny Geys, "Explaining voter turnout: A meta-analysis of national and subnational elections," Electoral Studies, 2016, 42, 264-275.

Cantoni, Davide, David Y. Yang, Noam Yuchtman, and Y. Jane Zhang, "Protests as Strategic Games: Experimental Evidence from Hong Kong's Antiauthoritarian Movement," Quarterly Journal of Economics, January 2019, 134 (2), 1021-1077.

Coate, Stephen and Michael Conlin, "A Group Rule-Utilitarian Approach to Voter Turnout: Theory and Evidence," American Economic Review, 2004, 94 (5), 1476-1504.

_ , , , and Andrea Moro, "The performance of pivotal-voter models in small-scale elections: Evidence from Texas liquor referenda," Journal of Public Economics, April 2008, 92 (3-4), 582-596.

Cox, Gary W. and Michael C. Munger, "Closeness, Expenditures, and Turnout in the 1982 U.S. House Elections," American Political Science Review, March 1989, 83 (1), 217.

Dale, Allison and Aaron Strauss, "Don't Forget to Vote: Text Message Reminders as a Mobilization Tool," American Journal of Political Science, October 2009, 53 (4), 787-804.

DellaVigna, Stefano and Ethan Kaplan, "The Fox News Effect: Media Bias and Voting," Quarterly Journal of Economics, August 2007, 122 (3), 1187-1234.

— , John A. List, Ulrike Malmendier, and Gautam Rao, "Voting to Tell Others," Review of Economic Studies, October 2016, 84 (1), 143-181.

Downs, Anthony, "An Economic Theory of Political Action in a Democracy," Journal of Political Economy, April 1957, 65 (2), 135-150.

Duffy, John and Margit Tavits, "Beliefs and Voting Decisions: A Test of the Pivotal Voter Model," American Journal of Political Science, July 2008, 52 (3), 603-618. 
Durante, Ruben, Paolo Pinotti, and Andrea Tesei, "The Political Legacy of Entertainment TV," American Economic Review, 2019, 109 (7), 2497-2530.

Enikolopov, Ruben, Aleksey Makarin, and Maria Petrova, "Social Media and Protest Participation: Evidence from Russia," Econometrica, July 2020, 88 (4), 1479-1514.

- and Maria Petrova, "Media Capture," in "Handbook of Media Economics," Vol. 1, Elsevier, 2015, pp. 687-700.

_, , , and Ekaterina Zhuravskaya, "Media and Political Persuasion: Evidence from Russia," American Economic Review, December 2011, 101 (7), 3253-3285.

Enos, Ryan D. and Anthony Fowler, "Pivotality and Turnout: Evidence from a Field Experiment in the Aftermath of a Tied Election," Political Science Research and Methods, 2014, 2 (2), 309-319.

Feddersen, Timothy and Alvaro Sandroni, "A Theory of Participation in Elections," American Economic Review, August 2006, 96 (4), 1271-1282.

Fujiwara, Thomas, Kyle Meng, and Tom Vogl, "Habit Formation in Voting: Evidence from Rainy Elections," American Economic Journal: Applied Economics, October 2016, 8 (4), 160-188.

Funk, Patricia, "Social Incentives and Voter Turnout: Evidence from the Swiss Mail Ballot System," Journal of the European Economic Association, September 2010, 8 (5), 1077-1103.

Gentzkow, Matthew, “Television and Voter Turnout," Quarterly Journal of Economics, August 2006, 121 (3), 931-972.

- , Jesse Shapiro, and Michael Sinkinson, "The Effect of Newspaper Entry and Exit on Electoral Politics," American Economic Review, December 2011, 101 (7), 2980-3018.

Gerber, Alan S. and Donald P. Green, "The Effects of Canvassing, Telephone Calls, and Direct Mail on Voter Turnout: A Field Experiment," American Political Science Review, September 2000, 94 (03), 653-663.

_ , Jonathan Gruber, and Daniel M Hungerman, "Does church attendance cause people to vote? Using blue laws' repeal to estimate the effect of religiosity on voter turnout," British Journal of Political Science, July 2016, 46 (3), 481-500.

_ , Mitchell Hoffman, John Morgan, and Collin Raymond, “One in a Million: Field Experiments on Perceived Closeness of the Election and Voter Turnout," American Economic Journal: Applied Economics, July 2020, 12 (3), 287-325.

González, Felipe, "Collective Action in Networks: Evidence from the Chilean Student Movement," Journal of Public Economics, August 2020, 188.

Hoffman, Mitchell, Gianmarco León, and Maria Lombardi, "Compulsory Voting, Turnout, and Government Spending: Evidence from Austria," Journal of Public Economics, January 2017, 145, 103-115.

Kirchgässner, Gebhard and Tobias Schulz, "Was treibt Stimmbuerger an die Urne? Eine empirische Untersuchung der Abstimmungsbeteiligung in der Schweiz, 1981-1999," Swiss Political Science Review, 2005, 11 (1), 1-56. 
Kriesi, Hanspeter, "Sind Abstimmungen käuflich?," in Adrian Vatter, Frédéric Varone, and Fritz Sager, eds., Demokratie als Leidenschaft. Planung, Entscheidung und Vollzug in der schweizerischen Demokratie, Bern: Haupt, 2009.

León, Gianmarco, "Turnout, Political Preferences and Information: Experimental Evidence from Perú," Journal of Development Economics, July 2017, 127, 56-71.

Levine, David K. and Thomas R. Palfrey, "The Paradox of Voter Participation? A Laboratory Study," American Political Science Review, February 2007, 101 (01), 143-158.

Linder, Wolf, Swiss Democracy: Possible Solutions to Conflict in Multicultural Societies, 3rd Edition, Basingstoke: Palgrave Macmillan, 2010.

Madestam, Andreas, Daniel Shoag, Stan Veuger, and David Yanagizawa-Drott, "Do Political Protests Matter? Evidence from the Tea Party Movement," Quarterly Journal of Economics, November 2013, 128 (4), 1633-1685.

Matsusaka, John G., "Election closeness and voter turnout: Evidence from California ballot propositions," Public Choice, August 1993, 76 (4), 313-334.

Morton, Rebecca B., Daniel Muller, Lionel Page, and Benno Torgler, "Exit polls, turnout, and bandwagon voting: Evidence from a natural experiment," European Economic Review, July 2015, $77,65-81$.

Myatt, David P., “A Theory of Voter Turnout," September 2015. London Business School Working Paper.

Ortoleva, Pietro and Erik Snowberg, "Overconfidence in Political Behavior," American Economic Review, February 2015, 105 (2), 504-535.

Perez-Truglia, Ricardo and Guillermo Cruces, "Partisan Interactions: Evidence from a Field Experiment in the United States," Journal of Political Economy, August 2017, 125 (4), 1208-1243.

Pons, Vincent and Clémence Tricaud, "Expressive Voting and Its Cost: Evidence From Runoffs With Two or Three Candidates," Econometrica, 2018, 86, 1621-1649.

Riker, William H. and Peter C. Ordeshook, "A Theory of the Calculus of Voting," American Political Science Review, March 1968, 62 (01), 25-42.

Rogers, Todd and Don Moore, "It's Close But We're Losing: The Motivating Power of UnderConfidence," Proceedings of the Academy of Management, 2015.

Schuessler, Alexander A., A logic of expressive choice, Princeton: Princeton University Press, 2000.

Shachar, Ron and Barry Nalebuff, "Follow the Leader: Theory and Evidence on Political Participation," American Economic Review, June 1999, 89 (3), 525-547.

Spenkuch, Jörg L and David Toniatti, "Political Advertising and Election Results," The Quarterly Journal of Economics, November 2018, 133 (4), 1981-2036.

Strömberg, David, "Radio's impact on public spending," Quarterly Journal of Economics, 2004, 119 (1), 189-221. 
Figures and Tables

Figure 1: Turnout, Closeness, Issue Type, AND the Political Supply Side
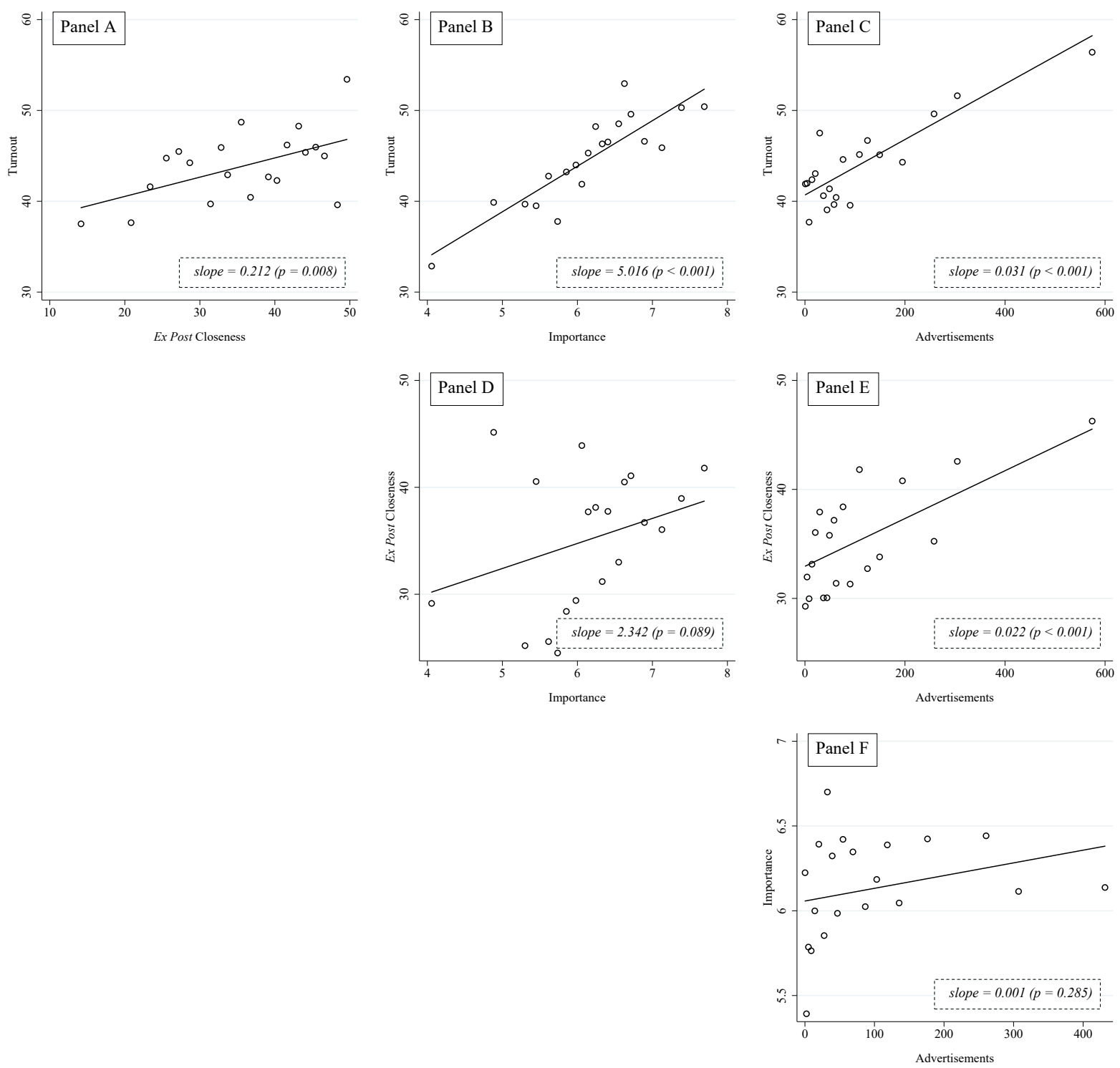

Notes: The matrix of binned scatter plots shows pairwise correlations of turnout, ex post closeness, vote importance and political advertisements at the vote (i.e., election) level. Turnout is the number of votes cast, as a percentage of eligible voters at the national level. Ex Post Closeness is the vote share of the losing side in percent. Importance is the self-reported personal importance attached by respondents of the VOX/VOTO surveys to a vote, on a scale from 0 to 10. Advertisements is the count of political ads in the six major Swiss newspapers (NZZ, Tages-Anzeiger, Blick, Tribune de Genève, Le Temps, Le Matin) during the four weeks preceding election day. Lines represent the bivariate linear fit with reported slope parameters estimated by simple OLS using heteroskedasticity-robust standard errors. Reported p-values refer to a test that the slope parameter is equal to zero. 
Figure 2: Unconditional Turnout Before ANd After Poll Release
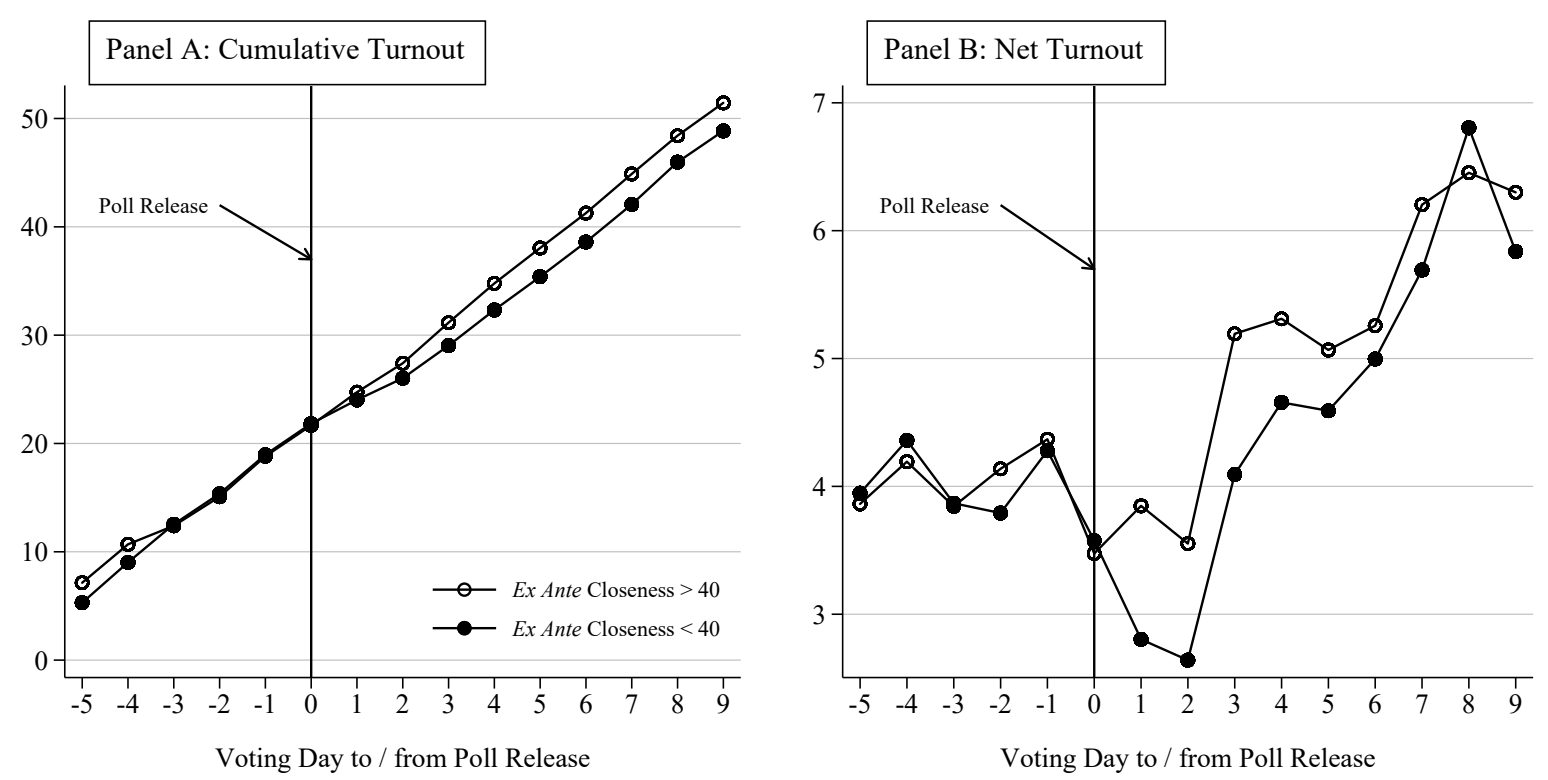

Notes: Panel A plots daily cumulative turnout, i.e., the percentage share of Genevan voters who turned out at or before a given voting day, separately for votes with ex ante poll closeness above or below the sample median of 40 (i.e., a losing side vote share above or below 40). Panel B shows an analogous plot for net turnout, i.e., the daily inflow of ballots divided by the stock of remaining voters (who did not turn out before a given voting day). The sample is an unbalanced panel of 52 votes observed from 5 voting days before to 9 voting days after poll release. 
Figure 3: The Effect of Closer Polls on Net Voter Turnout: Event-STudy Baseline

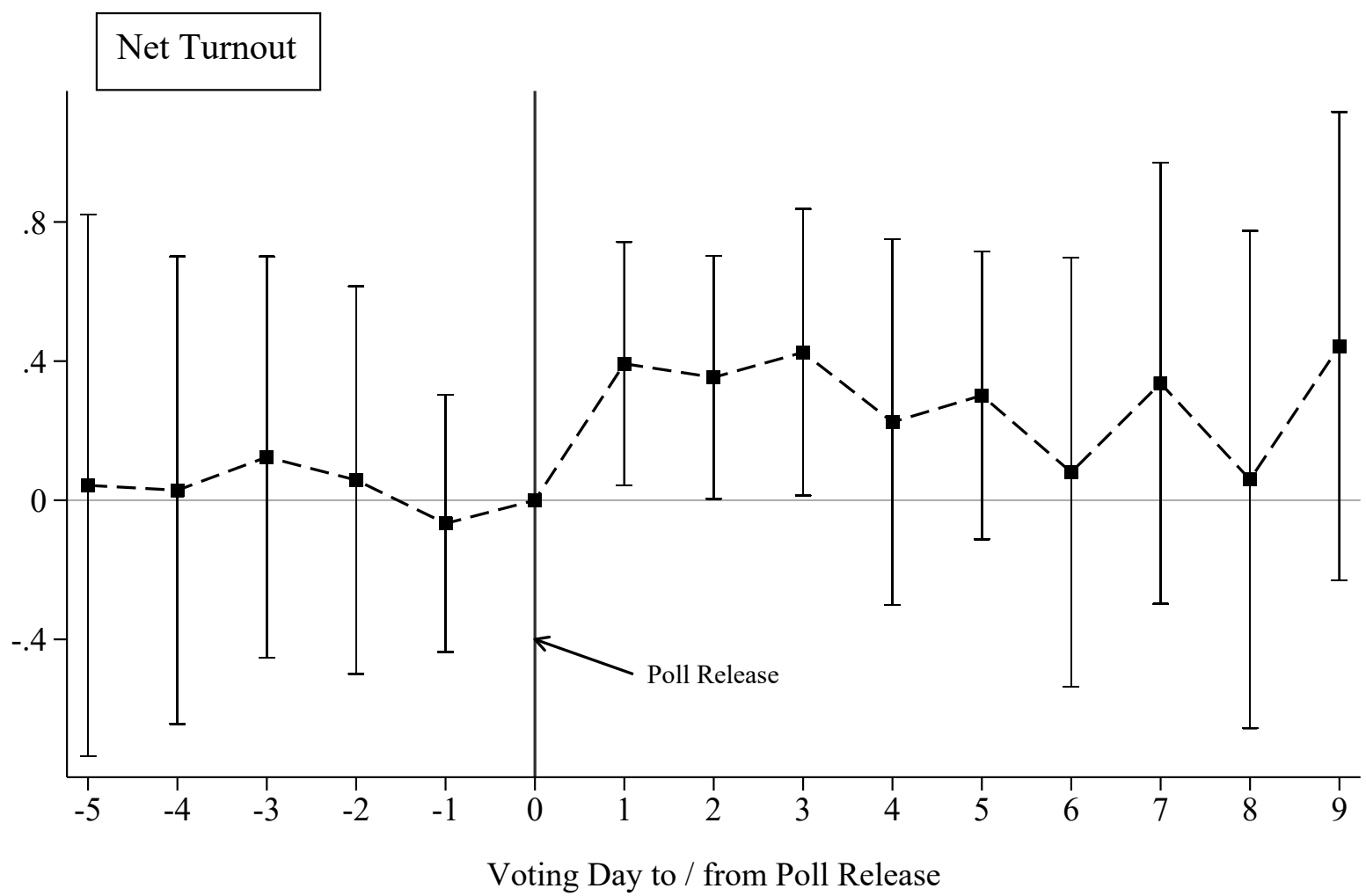

Notes: The event study graph plots day-specific effects of a one standard deviation increase in ex ante (poll) closeness on net turnout, i.e., the daily inflow of ballots in the canton of Geneva divided by the number of remaining Genevan voters who did not turn out before a given voting day, conditional on vote and voting day fixed effects. Squares represent coefficients and spikes depict 95\% confidence intervals from OLS estimates (reported in Online Appendix Table A.3, Column 1). The sample is an unbalanced panel of 52 votes observed from 5 voting days before to 9 voting days after poll release, where the day of poll release is the omitted category of reference. 


\section{Figure 4: The EFfect of Closer Polls on Net Voter Turnout: Event-STudy ROBUSTNESS}
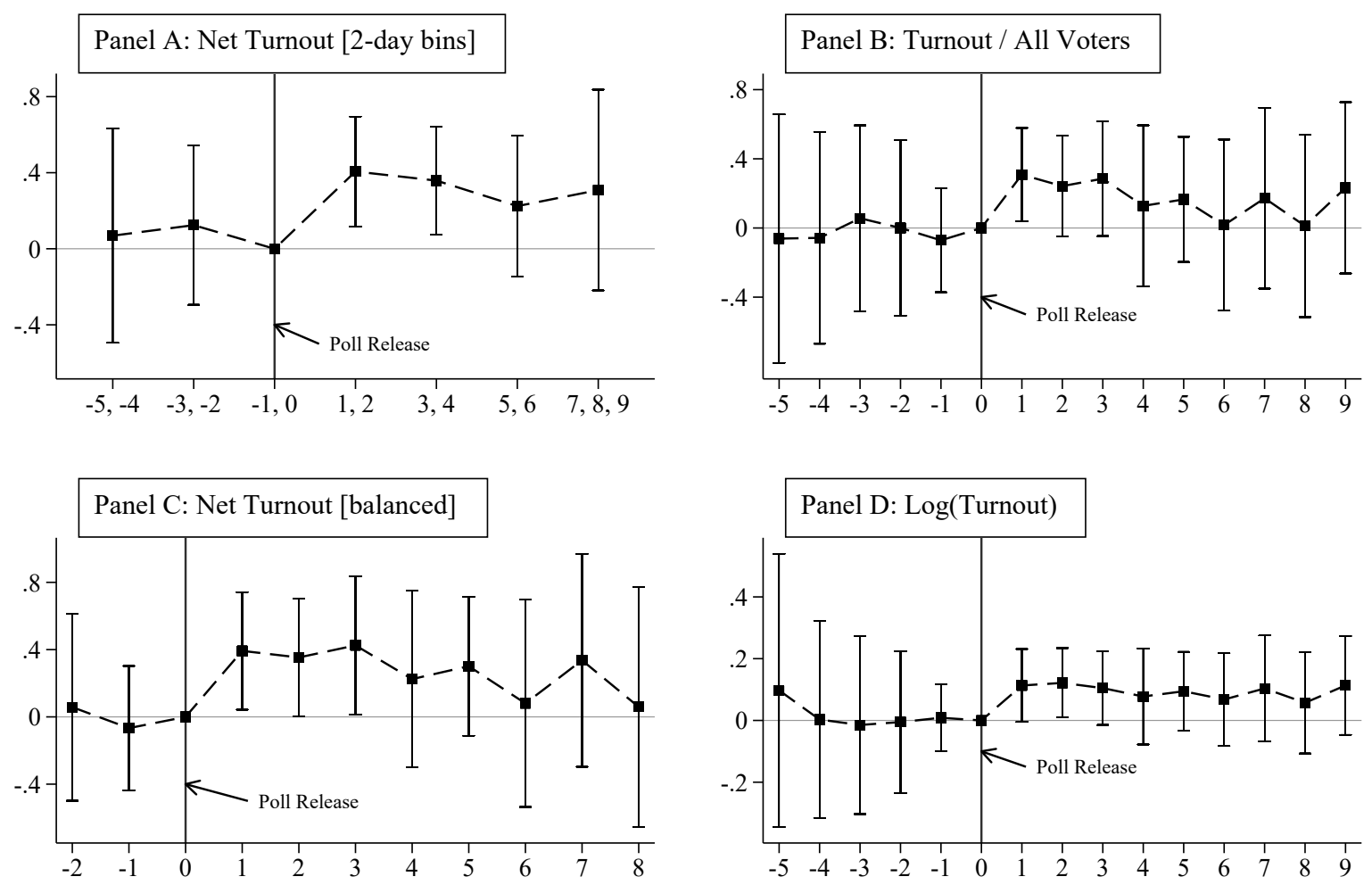

Notes: The figure shows variants of the event study graph presented in Figure 3. Panel A plots coefficients and 95\% confidence intervals for bins of two voting days, reported in Online Appendix Table A.4, Column 1, using the day of poll release as well as the day just before poll release as the omitted category of reference. Panel B uses the daily inflow of ballots divided by all eligible Genevan voters as an alternative measure of turnout, and plots OLS estimates reported in Online Appendix Table A.3, Column 3. Panel C drops all voting days in which not every vote has ballots counted, and instead uses a balanced panel of 52 votes observed from 2 voting days before to 8 voting days after poll release. Panel D uses the natural logarithm of the daily number of incoming ballots in the canton of Geneva as an alternative measure of turnout, and plots OLS estimates reported in Online Appendix Table A.4, Column 5. 
Figure 5: The EfFect of Closer Polls on Political Advertisements: Event-STudy

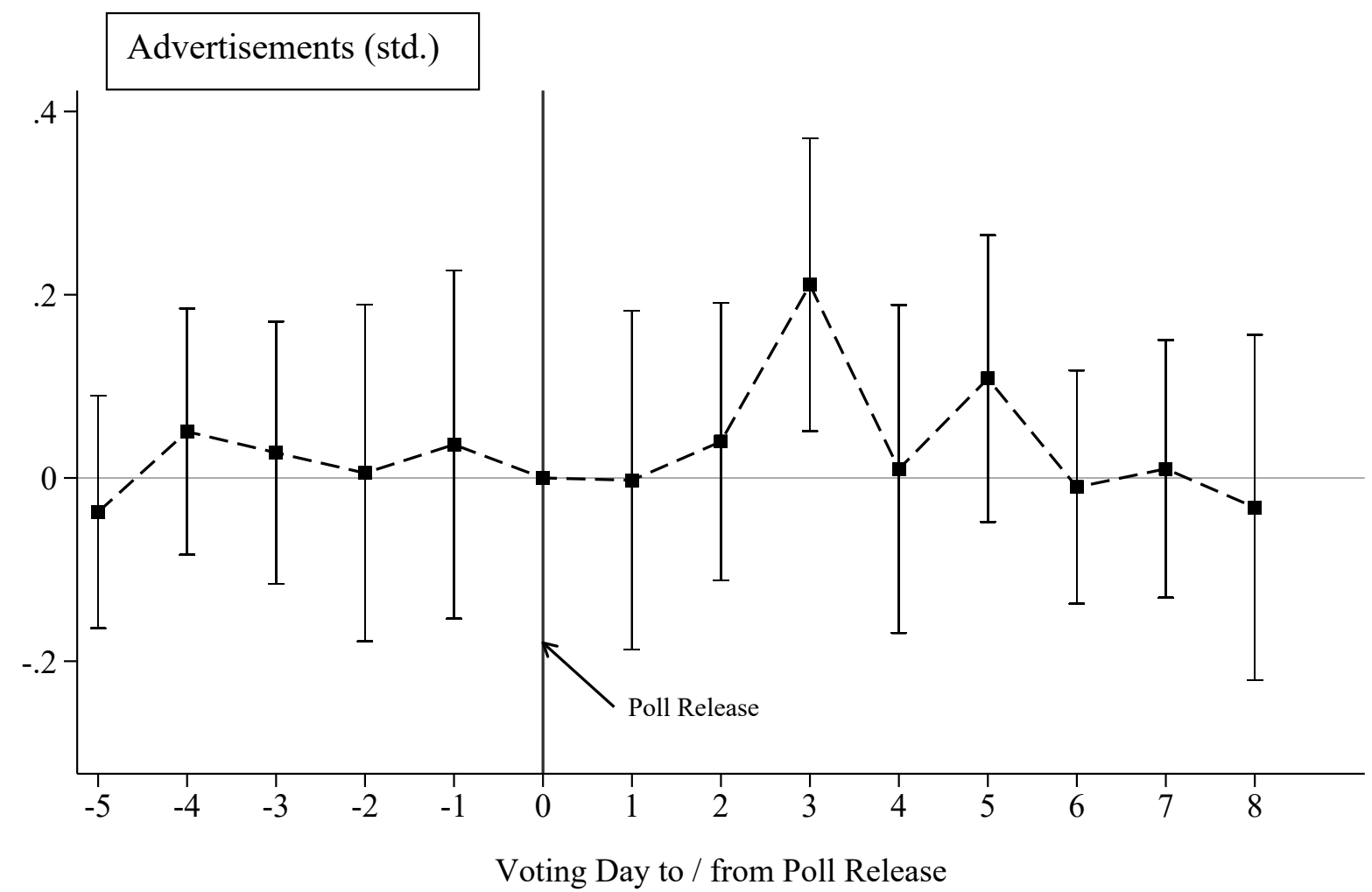

Notes: The event study graph replicates Figure 3 with a standardized measure of political campaigning activity as the outcome. It plots day-specific effects of a one standard deviation increase in ex ante (poll) closeness on the standardized number of political advertisements in Geneva's two major newspapers (Tribune de Genève, Le Temps), conditional on vote fixed effects and voting day fixed effects. The sample is an unbalanced panel of 52 votes observed from 5 voting days before to 8 voting days after poll release, where the day of poll release is the omitted category of reference. The last voting day of each vote is dropped because there are no Sunday editions of Geneva's major newspapers. 
Figure 6: The EFFect of Closeness on TuRnOUt by Municipality UnREPRESENTATIVENESS, BEFORE AND AFTER THE INTRODUction OF POLls
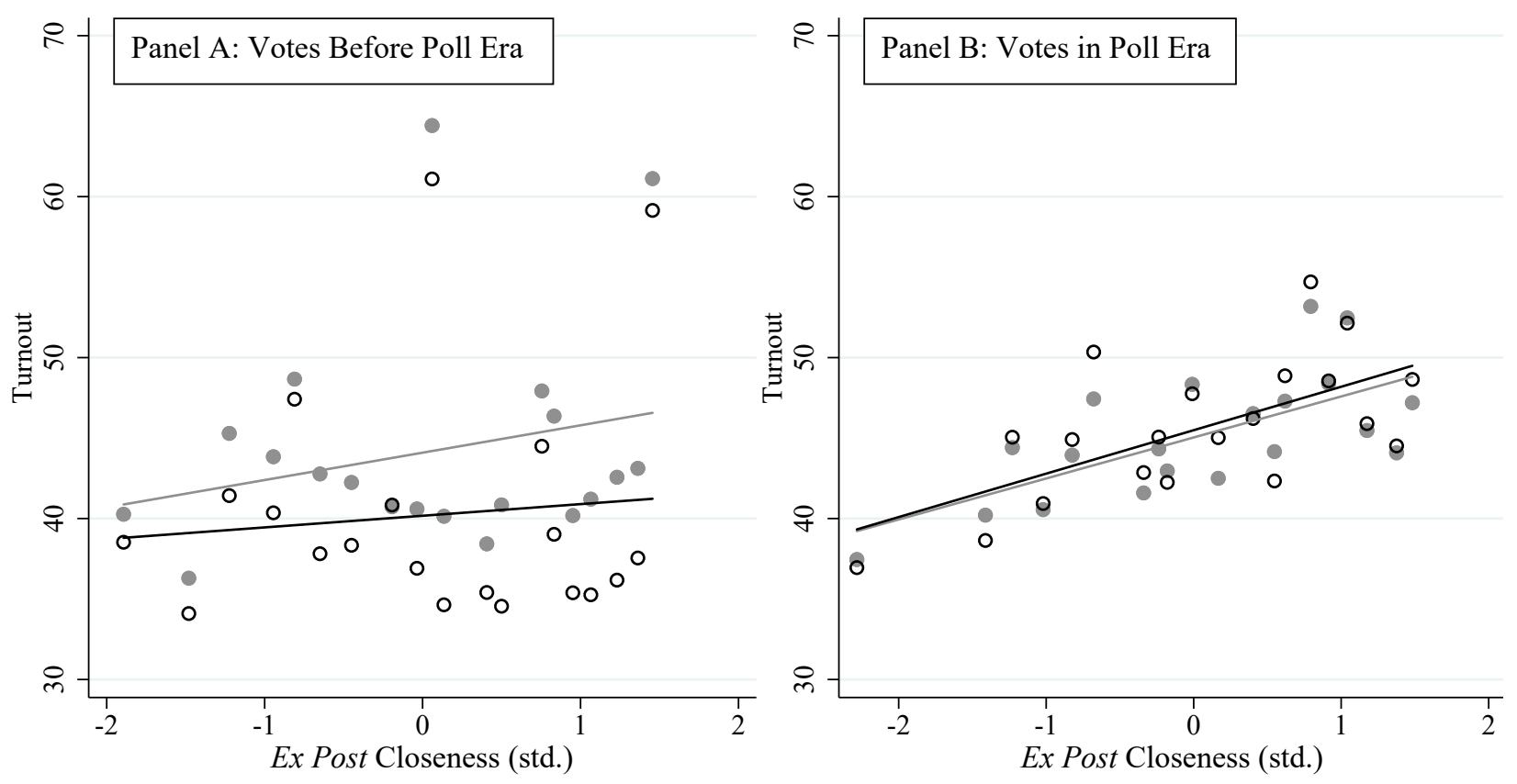

\begin{tabular}{|cllr|}
\hline & & Slopes Before Poll Era & \multicolumn{1}{c|}{ Slopes in Poll Era } \\
$-\quad \circ \quad$ Unrepresentative Municipalities & $0.724(\mathrm{p}=0.646)$ & $2.699(\mathrm{p}=0.005)$ \\
& Representative Municipalities & $1.700(\mathrm{p}=0.244)$ & $2.547(\mathrm{p}=0.005)$ \\
& Differences within Era: & $-0.976(p=0.010)$ & $0.152(p=0.693)$ \\
& Difference in Differences: & & $1.128(p=0.037)$ \\
\hline
\end{tabular}

Notes: Panel A shows binned scatter plots correlating municipality-level voter turnout and national-level ex post closeness, splitting the sample of municipalities above and below median political unrepresentativeness, for 46 votes in the era before pre-election polls were introduced. Panel B replicates Panel A for 69 votes in the era with pre-election polls. Unrepresentativeness is a municipality's historical tendency to produce voting results unrepresentative of nationallevel closeness, measured as the negative of the correlation coefficient between municipality-level and national-level $e x$ post closeness of voting results in the era before pre-election polls were introduced. Estimates of slope parameters as well as p-values associated with tests that (differences in) slopes equal zero are obtained from an OLS regression using all 115 votes, with standard errors clustered at vote level. 
Figure 7: Marginal Effects of Newspaper Poll Mentions Depending on Poll CLOSENESS

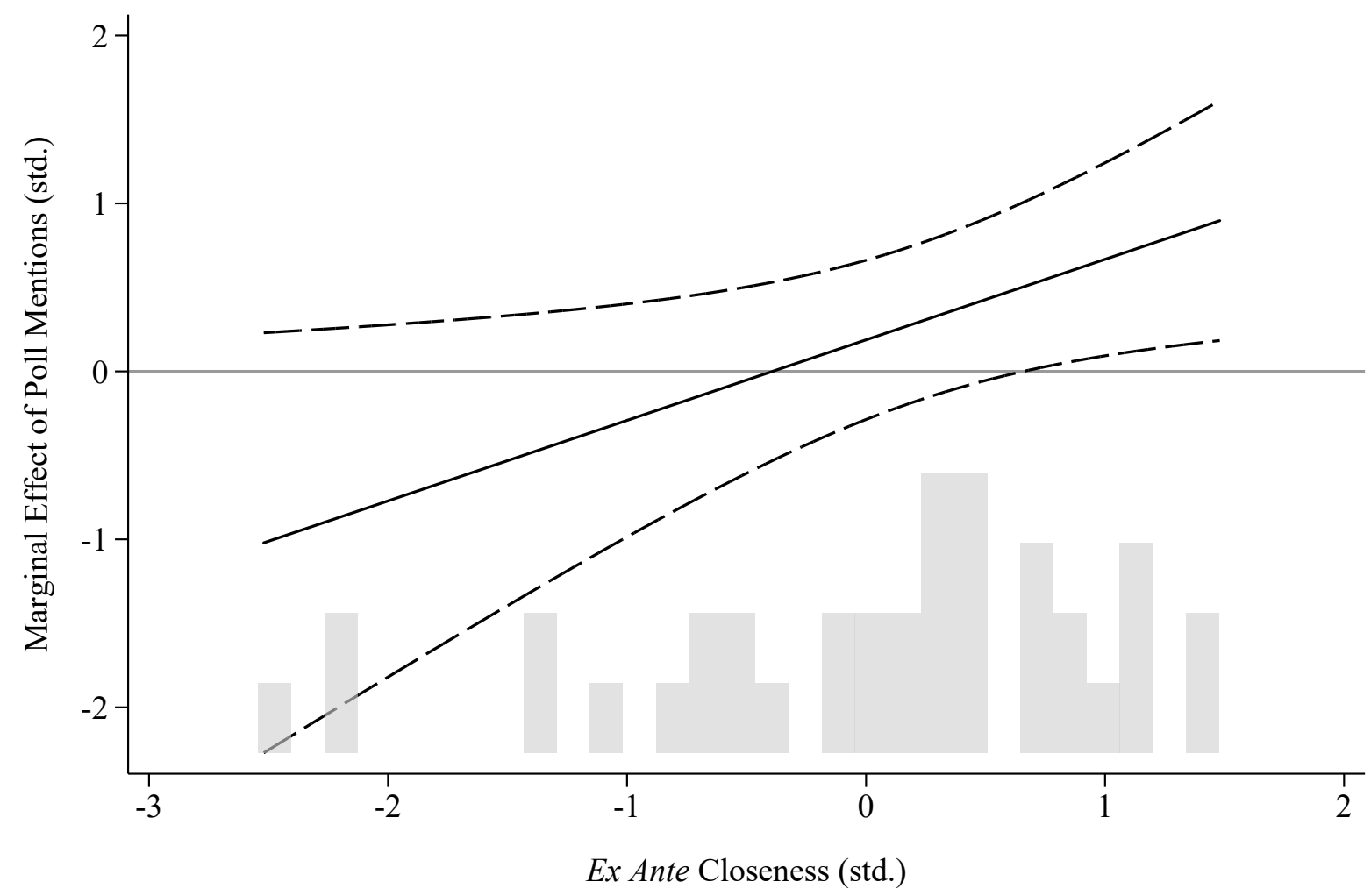

Notes: The solid line plots the total effect of a one standard deviation increase in poll mentions in cantonal newspapers on cantonal turnout depending on standardized ex ante (poll) closeness. Dashed lines represent $95 \%$ confidence intervals. The plot is based on OLS estimates reported in Table 4, Panel A, Column 1. The histogram shows the distribution of (standardized) ex ante (poll) closeness across votes. 
TABle 1: EXAMPLES Of ELECTION DAYS AND MOST IMPORTANT Votes

\begin{tabular}{|c|c|c|c|}
\hline Date & Vote Title & NZZ Mentions & Vote Importance (Survey) \\
\hline 1994-09-25 & Federal Penal Code and Military Penal Code (Racial Discrimination) & 39 & 6.12 \\
\hline 1994-09-25 & Federal Decision Abolishing Subsidies for Domestic Breadstuff from Tariff Revenues & 16 & 3.48 \\
\hline 2001-03-04 & Initiative "Yes to Europe!" & 68 & 6.61 \\
\hline 2001-03-04 & Initiative "for Lower Prices of Pharmaceuticals" & 53 & 5.79 \\
\hline 2001-03-04 & Initiative "for Road Safety with $30 \mathrm{~km} / \mathrm{h}$ in Built-Up Areas" & 36 & 5.53 \\
\hline 2009-11-29 & Initiative "against the Construction of Minarets" & 112 & 6.91 \\
\hline 2009-11-29 & Initiative "for a Ban on Exports of War Material" & 47 & 6.28 \\
\hline 2009-11-29 & Federal Decision on Special Funding for Air Traffic & 27 & 3.85 \\
\hline 2019-05-19 & Federal Act on Tax Reform and Funding for Old Age Insurance & 77 & 7.42 \\
\hline 2019-05-19 & Federal Decision Adopting the EU Directive on Gun Control & 13 & 6.49 \\
\hline
\end{tabular}

Notes: NZZ Mentions measures the number of times a vote was mentioned in the NZZ newspaper in the three months preceding election day. Vote Importance measures the average personal importance attached by VOX/VOTO survey respondents to a vote, on a 0-10 scale (10 indicating maximum imortance). 
TABLE 2: SUMMARY STATISTICS

\begin{tabular}{lccccc}
\hline \hline & & & & & \\
PANEL A: Vote $\times$ DAY-LEVEL DATA (GENEVA) & Mean & Std. Dev. & Min. & Max. & Obs. \\
\hline Net Turnout (\%) & 4.58 & 1.96 & 0.02 & 16.75 & 757 \\
Turnout / All Voters (\%) & 3.32 & 1.33 & 0.02 & 12.76 & 757 \\
Log(Turnout) & 8.76 & 0.56 & 3.91 & 10.02 & 757 \\
Cumulative Turnout (\%) & 28.19 & 14.24 & 0.02 & 62.90 & 757 \\
Ex Ante Closeness & 38.38 & 7.69 & 18.89 & 48.96 & 757 \\
Advertisements & 1.60 & 2.48 & 0.00 & 19.00 & 705 \\
\hline \hline & & & & & \\
PANEL B: VoTE-LEVEL DATA & & & & & \\
\hline Turnout (\%) & 43.78 & 8.33 & 27.60 & 78.78 & 115 \\
Ex Post Closeness & 35.30 & 9.75 & 8.03 & 49.91 & 115 \\
Importance & 6.13 & 0.87 & 3.22 & 7.79 & 83 \\
Advertisements & 107.56 & 145.18 & 0.00 & 1146.00 & 112 \\
\hline \hline & & & & & \\
PANEL C: MUNICIPALITY $\times$ VOTE-LEVEL DATA & & & & & \\
\hline Turnout (\%) & 44.00 & 13.02 & 3.20 & 100.00 & 250240 \\
Ex Post Closeness & 35.30 & 9.70 & 8.03 & 49.91 & 250240 \\
Poll Era & 0.60 & 0.49 & 0.00 & 1.00 & 250240 \\
Unrepresentativeness & -0.59 & 0.19 & -0.93 & 0.03 & 250240 \\
Homogeneity & 34.65 & 4.15 & 25.40 & 59.93 & 250240 \\
Electorate Size (in 1000) & 1.98 & 7.08 & 0.03 & 233.14 & 250240 \\
\hline \hline & & & & & \\
PANEL D: CANTON $\times$ VOTE-LEVEL DATA & & & & & \\
\hline Turnout $(\%)$ & 47.27 & 8.91 & 21.67 & 72.61 & 962 \\
Ex Ante Closeness & 37.88 & 7.47 & 18.89 & 48.91 & 962 \\
Poll Mentions & 2.28 & 3.42 & 0.00 & 24.00 & 962 \\
Incidental Poll Mentions & 3.04 & 0.00 & 20.00 & 962 \\
Incidental Poll Mentions (< 15\% Market Share) & 2.40 & 2.83 & 0.00 & 15.00 & 962 \\
Importance & 6.12 & 1.13 & 0.50 & 10.00 & 957 \\
Advertisements & 73.93 & 68.18 & 0.00 & 403.00 & 962 \\
\hline \hline
\end{tabular}

Notes: In each dataset, vote-specific variables refer to the most important vote per election day, as indicated by selfreported importance in VOX/VOTO surveys, or, for years prior to the existence of survey measures, by the number of vote mentions in the NZZ in the three months preceding the vote. Vote $\times$ Day-level Data: Net Turnout measures turnout as the daily number of votes cast, in percent of eligible voters not having cast their vote on earlier days. Turnout / All Voters is the daily number of votes cast, in percent of eligible voters. Log(Turnout) is the natural logarithm of the daily number of votes cast. Cumulative Turnout is the daily running total of votes cast, in percent of eligible voters. Ex Ante Closeness measures the losing side's vote share at the federal level in percent, as predicted by the pre-election poll, and varies from 0 to 50 (50 indicating maximum closeness). Advertisements is the daily count of political ads placed in the two major Genevan newspapers (Tribune de Genève, Le Temps). Vote-level Data: Turnout is the number of votes cast, in percent of eligible voters at the federal level. Ex Post Closeness is the vote share of the losing side at the federal level. Importance measures the average personal importance attached by VOX/VOTO survey respondents to a vote, on a 0-10 scale (10 indicating maximum importance). Advertisements is the number of political ads placed in the six major Swiss newspapers (NZZ, Tages-Anzeiger, Blick, Tribune de Genève, Le Temps, Le Matin) in the four weeks preceding election day. Municipality $\times$ Vote-level Data: Turnout is the number of votes cast, in percent of eligible voters at the municipal level. Ex Post Closeness defined as in vote-level data. Poll Era is a dummy variable equal to 1 for the 69 votes held after the introduction of pre-election polls. Unrepresentativeness is a municipality's historical tendency to produce voting results unrepresentative of national-level closeness, measured as the negative of the correlation coefficient between municipality-level and national-level ex post closeness of voting results before preelection polls were introduced. Homogeneity is a municipality's historical tendency to produce voting results distant from 50-50 outcomes, measured as the average municipal-level margin of majority across all votes held before preelection polls were introduced. Electorate Size is the average number of eligible voters (in 1000) in a municipality across votes held before pre-election polls were introduced. Canton $\times$ Vote-level Data: Turnout measures cantonal turnout as the number of votes cast, in percent of eligible voters. Ex Ante Closeness defined and measured as in day $\times$ vote-level data. Poll Mentions is the number of times the pre-election poll for a vote is mentioned in cantonal newspapers read by at least $10 \%$ of a canton's inhabitants. Incidental Poll Mentions are poll mentions in cantonal newspapers whose largest market is in another canton. Incidental Poll Mentions ( $<15 \%$ Market Share) are poll mentions in cantonal newspapers, excluding newspapers for which the canton is either the largest market or makes for more than $15 \%$ of the newspaper's readership. Importance measures the average personal importance attached by a canton's VOX survey respondents to a vote. Advertisements is the number of political ads placed in cantonal newspapers in the month preceding election day. 
TAble 3: Heterogeneous EfFects of Election Closeness and Polls Depending on MUNICIPALITY UNREPRESENTATIVENESS

\begin{tabular}{lcc}
\hline \hline & $(1)$ & $(2)$ \\
\hline Ex Post Closeness (std.) $\times$ Unrepresentativeness (std.) & $-0.5676^{* * *}$ & $-0.5696^{* * *}$ \\
& $(0.2132)$ & $(0.2156)$ \\
Ex Post Closeness (std.) $\times$ Unrepresentativeness (std.) $\times$ Poll Era & $0.6211^{* *}$ & $0.6179^{* *}$ \\
& $(0.2983)$ & $(0.3003)$ \\
Unrepresentativeness (std.) $\times$ Poll Era & $1.9756^{* * *}$ & $2.0288^{* * *}$ \\
& $(0.2613)$ & $(0.2629)$ \\
\hline Test for Convergence (p-value) & 0.798 & 0.818 \\
\hline R-squared & 0.697 & 0.698 \\
Observations & 250240 & 250240 \\
Municipality Fixed Effects & $\mathrm{Y}$ & $\mathrm{Y}$ \\
Vote Fixed Effects & $\mathrm{Y}$ & $\mathrm{Y}$ \\
Electorate Size & $\mathrm{N}$ & $\mathrm{Y}$ \\
\hline \hline
\end{tabular}

Notes: Each column presents results from an OLS regression with municipality-level voter turnout as the dependent variable. Unrepresentativeness is a municipality's historical tendency to produce voting results unrepresentative of national-level closeness, measured by the negative of the correlation coefficient between muncipality-level and national-level ex post closeness of voting results in the era before pre-election polls. Poll Era is a dummy equal to $1 \mathrm{for}$ 69 votes held after the introduction of polls in 1998. Test for Convergence reports the p-value of an F-test that the sum of the coefficients on Ex Post Closeness (std.) $\times$ Unrepresentativeness (std.) and Ex Post Closeness (std.) $\times$ Unrepresentativeness (std.) $\times$ Poll Era (std.) equals 0 . Column 2 controls for a triple interaction among Ex Post Closeness, Poll Era and the standardized average municipality electorate size, as well as all lower order terms. The sample is a balanced panel of 2176 municipalities observed in 115 votes held from 1981 to 2019. Standard errors clustered at the vote level in parentheses: * $p<0.10,{ }^{* *} p<0.05,{ }^{* * *} p<0.01$. 
Table 4: Newspaper Coverage, Closeness and Cantonal Voter Turnout

\begin{tabular}{|c|c|c|c|c|c|c|}
\hline \multirow[b]{2}{*}{ Panel A: Poll Mentions in Cantonal Newspapers } & \multicolumn{2}{|c|}{ Turnout (\%) } & \multicolumn{2}{|c|}{ Advertisements (std.) } & \multicolumn{2}{|c|}{ Importance (std.) } \\
\hline & $(1)$ & $(2)$ & (3) & $(4)$ & (5) & (6) \\
\hline Poll Mentions (std.) $\times$ Ex Ante Closeness (std.) & $\begin{array}{c}0.4795^{* *} \\
(0.2170)\end{array}$ & $\begin{array}{c}0.5426^{* *} \\
(0.2010)\end{array}$ & $\begin{array}{c}0.0408 \\
(0.0378)\end{array}$ & $\begin{array}{c}0.0389 \\
(0.0377)\end{array}$ & $\begin{array}{c}0.0419 \\
(0.0506)\end{array}$ & $\begin{array}{c}0.0376 \\
(0.0509)\end{array}$ \\
\hline Poll Mentions (std.) & $\begin{array}{c}0.1877 \\
(0.2419)\end{array}$ & $\begin{array}{c}1.2549^{* *} \\
(0.6185)\end{array}$ & $\begin{array}{c}0.2266^{* * *} \\
(0.0526)\end{array}$ & $\begin{array}{l}0.1393^{* *} \\
(0.0658)\end{array}$ & $\begin{array}{c}0.0416 \\
(0.0597)\end{array}$ & $\begin{array}{c}0.0427 \\
(0.0953)\end{array}$ \\
\hline R-squared & 0.820 & 0.822 & 0.876 & 0.877 & 0.329 & 0.329 \\
\hline \multicolumn{7}{|l|}{ PANel B: InCidental Poll Mentions } \\
\hline Poll Mentions (std.) $\times$ Ex Ante Closeness (std.) & $\begin{array}{l}0.3741^{*} \\
(0.1928)\end{array}$ & $\begin{array}{c}0.4516^{* * *} \\
(0.1635)\end{array}$ & $\begin{array}{c}0.0287 \\
(0.0455)\end{array}$ & $\begin{array}{c}0.0519 \\
(0.0412)\end{array}$ & $\begin{array}{c}0.0479 \\
(0.0359)\end{array}$ & $\begin{array}{c}0.0328 \\
(0.0481)\end{array}$ \\
\hline Poll Mentions (std.) & $\begin{array}{l}-0.0818 \\
(0.2722)\end{array}$ & $\begin{array}{l}1.3947^{*} \\
(0.7391)\end{array}$ & $\begin{array}{c}0.2459^{* * *} \\
(0.0547)\end{array}$ & $\begin{array}{c}0.2977^{* * *} \\
(0.0857)\end{array}$ & $\begin{array}{c}0.0364 \\
(0.0594)\end{array}$ & $\begin{array}{c}0.0132 \\
(0.1122)\end{array}$ \\
\hline R-squared & 0.820 & 0.821 & 0.878 & 0.878 & 0.329 & 0.329 \\
\hline \multicolumn{7}{|l|}{ PANEl C: InCidental POll Mentions (<15\% Market Share) } \\
\hline Poll Mentions (std.) $\times$ Ex Ante Closeness (std.) & $\begin{array}{c}0.3835^{* *} \\
(0.1753)\end{array}$ & $\begin{array}{c}0.5380^{* * *} \\
(0.1752)\end{array}$ & $\begin{array}{c}0.0137 \\
(0.0465)\end{array}$ & $\begin{array}{c}0.0335 \\
(0.0441)\end{array}$ & $\begin{array}{c}0.0511 \\
(0.0335)\end{array}$ & $\begin{array}{c}0.0338 \\
(0.0398)\end{array}$ \\
\hline Poll Mentions (std.) & $\begin{array}{c}0.0234 \\
(0.2673)\end{array}$ & $\begin{array}{c}2.0387^{* *} \\
(0.8815)\end{array}$ & $\begin{array}{c}0.2361^{* * *} \\
(0.0554)\end{array}$ & $\begin{array}{c}0.2975^{* * *} \\
(0.0766)\end{array}$ & $\begin{array}{c}0.0133 \\
(0.0572)\end{array}$ & $\begin{array}{l}-0.0353 \\
(0.1110)\end{array}$ \\
\hline R-squared & 0.820 & 0.822 & 0.876 & 0.876 & 0.329 & 0.329 \\
\hline Observations & 962 & 962 & 962 & 962 & 957 & 957 \\
\hline German $\times$ Poll Mentions (std.) & $\mathrm{N}$ & $\mathrm{Y}$ & $\mathrm{N}$ & $\mathrm{Y}$ & $\mathrm{N}$ & $\mathrm{Y}$ \\
\hline German $\times$ Ex Ante Closeness (std.) & $\mathrm{N}$ & $\mathrm{Y}$ & $\mathrm{N}$ & Y & $\mathrm{N}$ & Y \\
\hline
\end{tabular}

Notes: Each panel presents results from six OLS regressions using three dependent variables: cantonal turnout (Columns 1 and 2), the standardized number of newspaper advertisements in cantonal newspapers (Columns 3 and 4), and standardized importance, as rated by a canton's average VOX survey responses (Columns 5 and 6 ). In Panel A, Poll Mentions (std.) refer to the standardized count of poll mentions in cantonal newspapers, i.e., newspapers read by at least $10 \%$ of a canton's inhabitants. In Panel B, only Incidental Poll Mentions are considered, i.e., mentions in cantonal newspapers whose main market lies in another canton. Panel $\mathrm{C}$ further restricts Incidental Poll Mentions to mentions in newspapers whose cantonal readership accounts for less than $15 \%$ of the newspaper's total readership. Ex Ante Closeness is the losing side's vote share at the federal level, as predicted by the pre-election poll. All specifications include canton and vote fixed effects. Columns 2, 4, and 6 additionally control for a dummy equal to one for German-speaking cantons, interacted with both Ex Ante Closeness (std.) and Poll Mentions (std.). The sample is a panel of 26 cantons, observed in 37 votes held between 2000 and 2014. Standard errors clustered at the vote level in parentheses: ${ }^{*} p<0.10,{ }^{* *} p<0.05,{ }^{* * *} p<0.01$. 
Table 5: Counterfactual Turnout and Vote Results

\begin{tabular}{|c|c|c|c|c|}
\hline PAnel A: Closer Poll for Losing Side & Actual Yes (\%) & Poll Yes (\%) & Counterfactual Yes $(\%)$ & Cantons \\
\hline Federal Act on Corporate Tax Reform (February 24, 2008) & 50.53 & 59.74 & 49.75 & \\
\hline Initiative "Limiting the Construction of Second Homes" (March 11, 2012) & 50.63 & 58.43 & 49.97 & \\
\hline \multicolumn{5}{|l|}{ PANEl B: LeSS Close POll FOR LEADING Side } \\
\hline Federal Act on Corporate Tax Reform (February 24, 2008) & 50.53 & 59.74 & 49.72 & \\
\hline Initiative “Limiting the Construction of Second Homes” (March 11, 2012) & 50.63 & 58.43 & 49.95 & \\
\hline \multicolumn{5}{|c|}{ Panel C: Higher Poll Coverage by Newspapers Supporting the Losing Side } \\
\hline Federal Act on the Army and Military Administration (June 10, 2001) & 50.99 & 59.49 & 49.97 & 10 \\
\hline Initiative "against Abuse of Asylum" (November 24, 2002) & 49.91 & 53.75 & 50.16 & 1 \\
\hline Federal Act on Corporate Tax Reform (February 24, 2008) & 50.53 & 59.74 & 49.91 & 3 \\
\hline Initiative "Limiting the Construction of Second Homes" (March 11, 2012) & 50.63 & 58.43 & 49.93 & 5 \\
\hline Initiative “against Mass Immigration” (February 9, 2014) & 50.33 & 46.24 & 49.89 & 2 \\
\hline \multicolumn{5}{|c|}{$\begin{array}{l}\text { Notes: Table lists the actual Yes vote share, the Yes vote share predicted by the pre-election poll, and the counterfactual Yes vote share, for all votes with election outcomes flipped by the } \\
\text { counterfactual exercises. Each panel corresponds to one counterfactual exercise. Panel A calculates counterfactual Yes vote shares assuming that voters supporting the losing side in the } \\
\text { pre-election poll observe a counterfactual pre-election poll overstating closeness by one standard deviation (i.e., by 7.69 percentage points) with respect to the actual pre-election poll, with } \\
\text { counterfactual closeness bounded above by 50. The implied increase in turnout of the losing side is } \Delta \text { closeness } \cdot \hat{\beta} / 100 \text {, where } \hat{\beta}=0.16 \text { ( } p<0.1) \text { is the slope coefficient from a simple OLS } \\
\text { regression of national-level turnout (\%) on ex ante (poll) closeness, in the sample of } 57 \text { most important votes with a pre-election poll. Panel B replicates Panel A, but assuming that voters } \\
\text { supporting the leading side observe a pre-election poll understating closeness by one standard deviation. Panel C calculates counterfactual Yes vote shares assuming that, in some cantons, } \\
\text { newspapers read by voters supporting the losing side in the election increase poll mentions to the sample maximum. The change in turnout of the losing side induced by the increase in poll } \\
\text { mentions is calculated using coefficients and the sample of } 37 \text { votes from Table 4, Panel A, Column } 1 \text {. Counterfactual Yes vote shares in panel C result from limiting the number of cantons } \\
\text { subject to the counterfactual to the minimum necessary to flip the outcome of the vote. The rightmost column reports the minimum number of cantons subject to the counterfactual newspaper } \\
\text { poll coverage required in order to flip the vote outcome. }\end{array}$} \\
\hline
\end{tabular}




\section{Online Appendix: Not for Publication}

Figure A.1: Media Usage for Political Opinion Formation

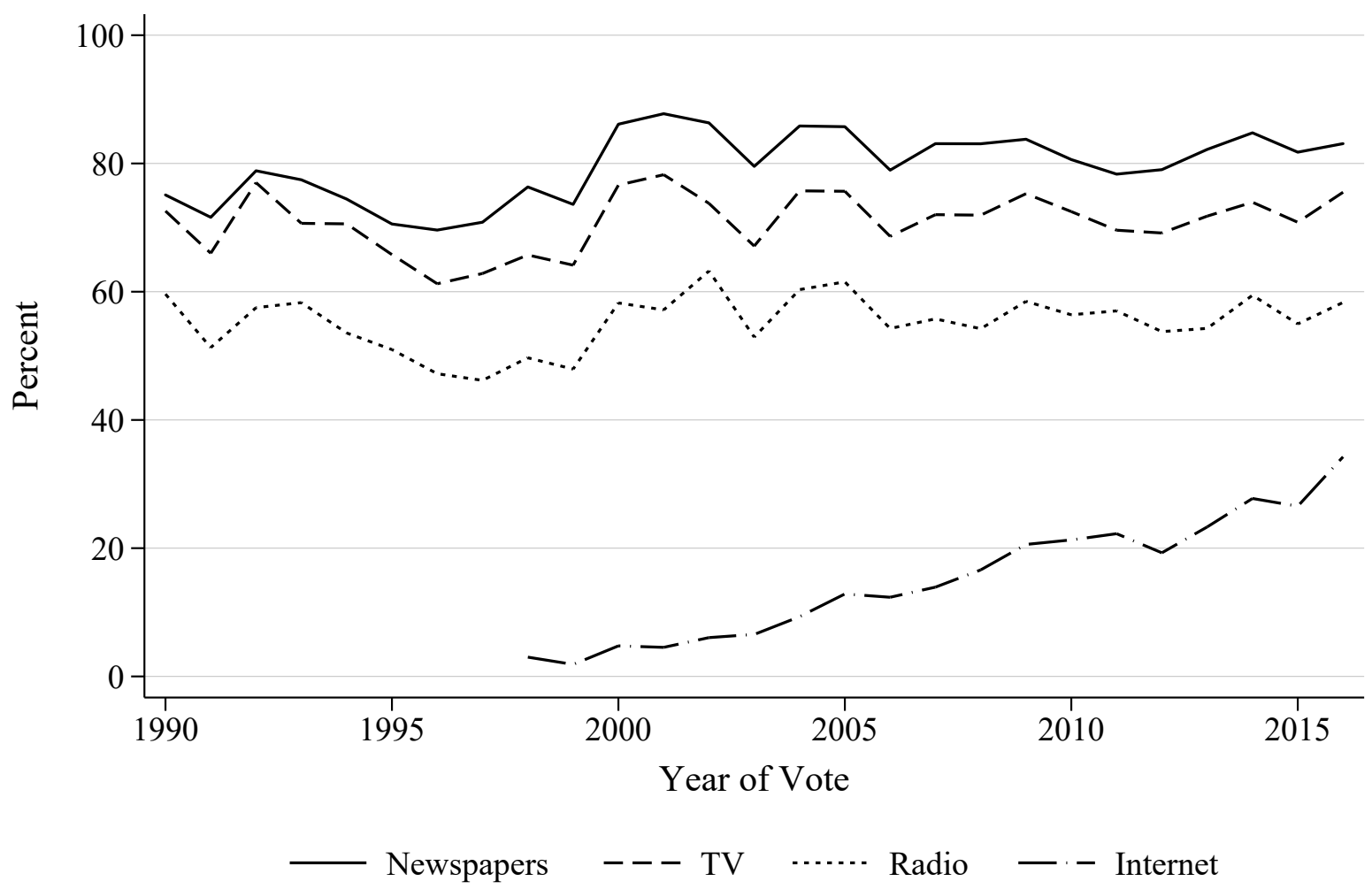

Notes: Responses from the VOX survey to the following prompt: "Through which media did you orient yourself and learn about the pros and cons of the last vote? Please indicate all possibilities that were accurate for the last vote." The graph shows the share of survey respondents who indicated the use of newspapers, TV, radio, or the Internet. 
Figure A.2: Endogeneous And Incidental Poll Mentions in CANTONS Over Time
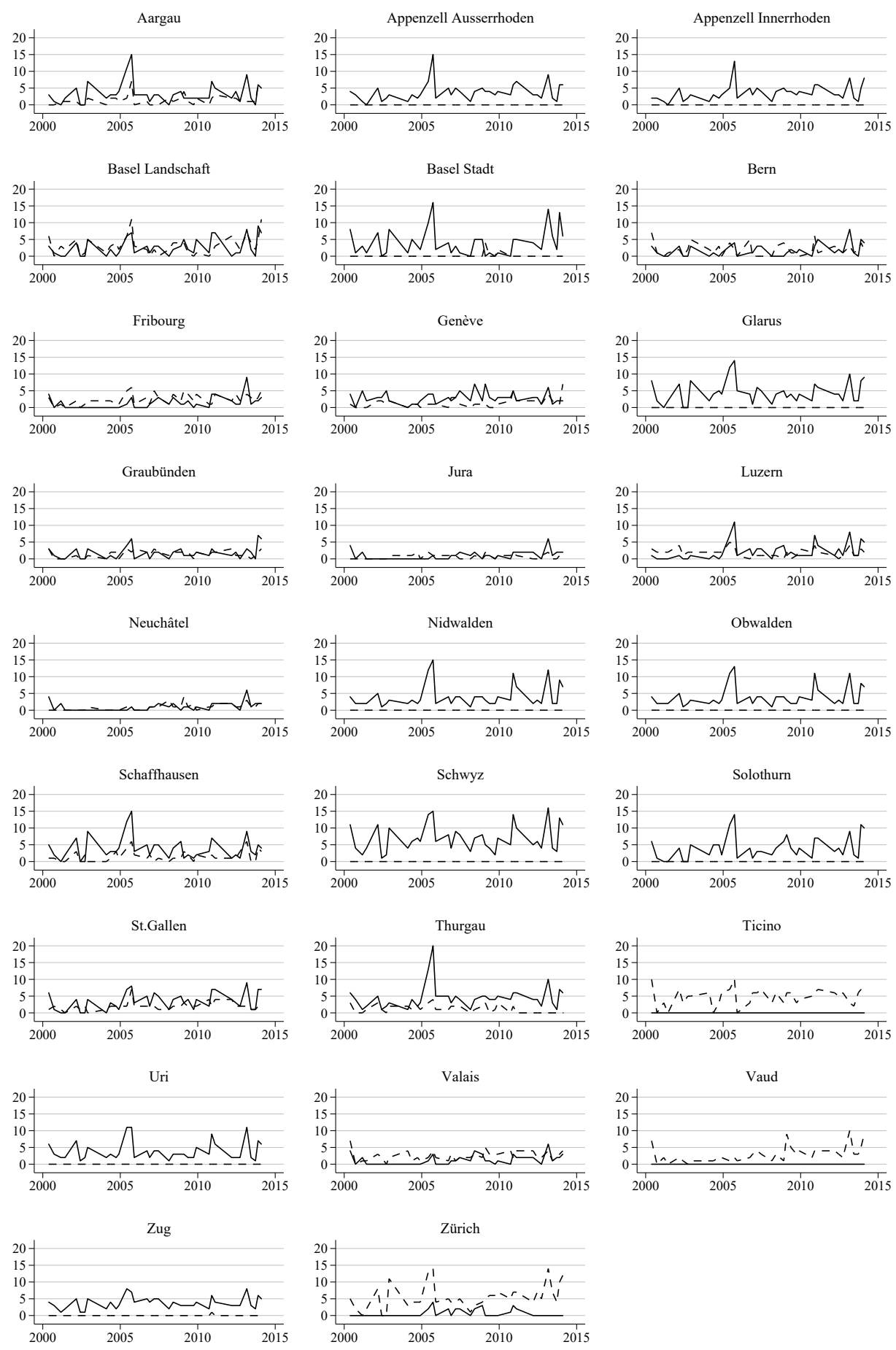

$$
\text { - - - - Endogenous Poll Mentions _ _ Incidental Poll Mentions }
$$

Notes: Each panel plots the number of endogenous and incidental poll mentions over time, for one canton. Endogenous Poll Mentions are poll mentions in newspapers read by at least $10 \%$ of a canton's inhabitants and for which the canton is the largest market. Incidental Poll Mentions are poll mentions in newspapers read by at least $10 \%$ of a canton's inhabitants, but whose largest market is in a different canton. 
Figure A.3: Distributions OF MUNiCIPALITY UNREPRESENTATIVENSS AND HOMOGENEITY
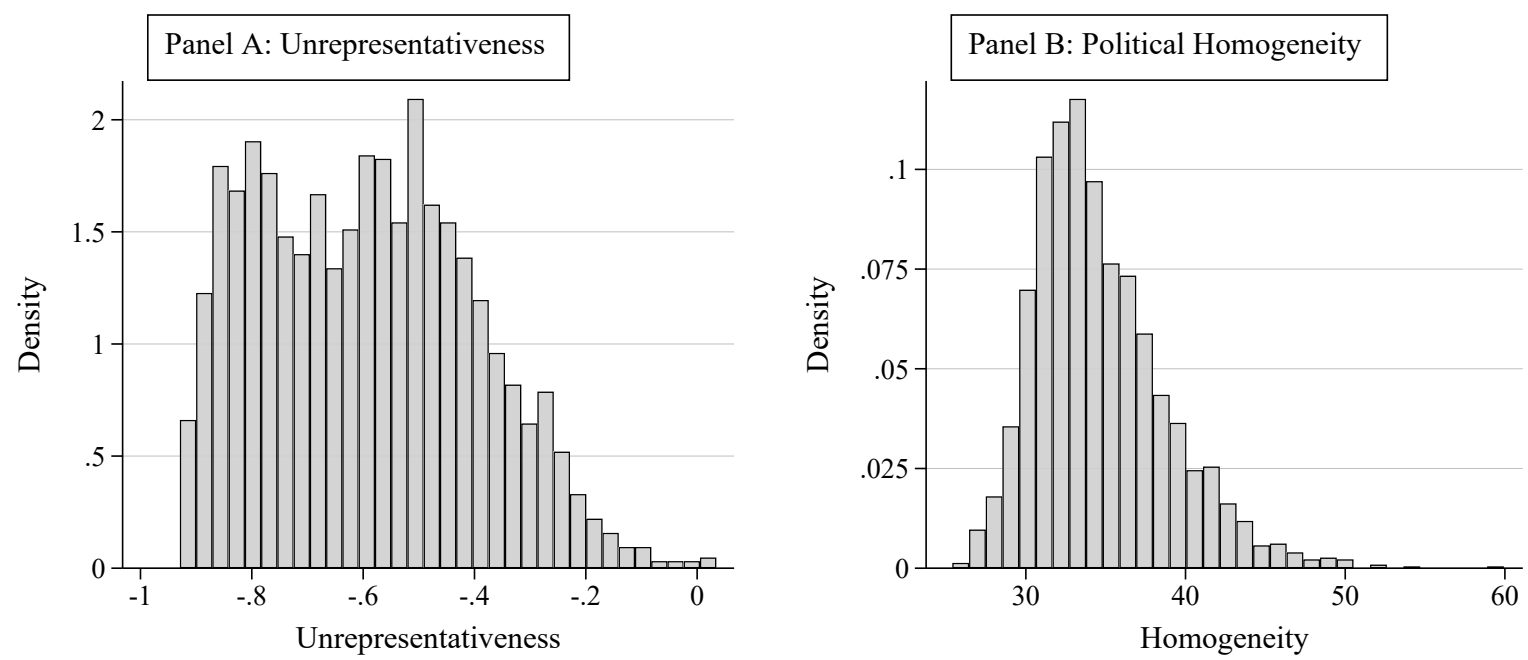

Notes: The figure shows the distribution of 2176 Swiss municipalities according to unrepresentativeness (panel A) and political homogeneity (panel B). Unrepresentativeness is a municipality's historical tendency to produce voting results unrepresentative of national-level closeness, measured as the negative of the correlation coefficient between municipality-level and national-level ex post closeness of voting results in the era before pre-election polls were introduced. Political homogeneity is a municipality's historical tendency to produce outcomes distant from 50-50, as measured by the average municipal-level margin of majority across all votes held in the era before pre-election polls were introduced. 
Figure A.4: The EfFect of Closeness on Turnout by Municipality Homogeneity, BEFORE AND AFTER THE INTRODUCTION OF POLLS
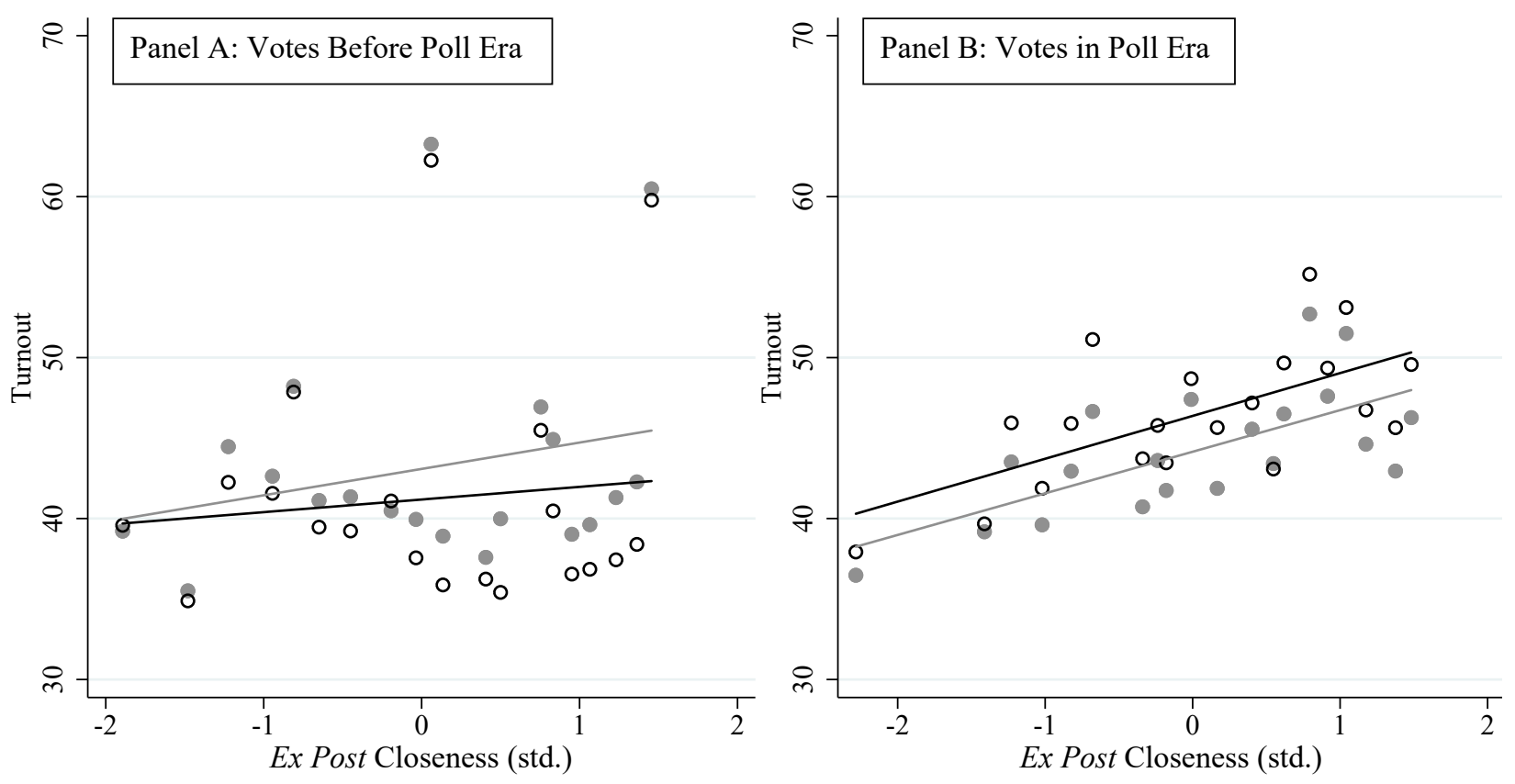

\begin{tabular}{|c|c|c|c|c|}
\hline \multirow{4}{*}{ - } & & & Slopes Before Poll Era & Slopes in Poll Era \\
\hline & 0 & Homogeneous Municipalities & $0.786(\mathrm{p}=0.612)$ & $2.661(p=0.005)$ \\
\hline & $\bullet$ & Heterogeneous Municipalities & $1.638(\mathrm{p}=0.267)$ & $2.585(\mathrm{p}=0.005)$ \\
\hline & & $\begin{array}{l}\text { Differences within Era: } \\
\text { Difference in Differences: }\end{array}$ & $-0.852(p=0.005)$ & $\begin{array}{l}0.077(p=0.800) \\
0.928(p=0.030)\end{array}$ \\
\hline
\end{tabular}

Notes: Panel A shows binned scatter plots correlating municipality-level voter turnout and national-level ex post closeness, splitting the sample of municipalities above and below median political homogeneity, for 46 votes in the era before pre-election polls were introduced. Panel B replicates Panel A for 69 votes in the era with pre-election polls. Political homogeneity is a municipality's historical tendency to produce outcomes distant from 50-50, as measured by the average municipal-level margin of majority across all votes held in the era before pre-election polls. Estimates of slope parameters as well as p-values associated with tests that (differences in) slopes equal zero are obtained from an OLS regression using all 115 votes, with standard errors clustered at vote level. 
Figure A.5: Predicted Probability of a Clinton Victory By Outlet Slant

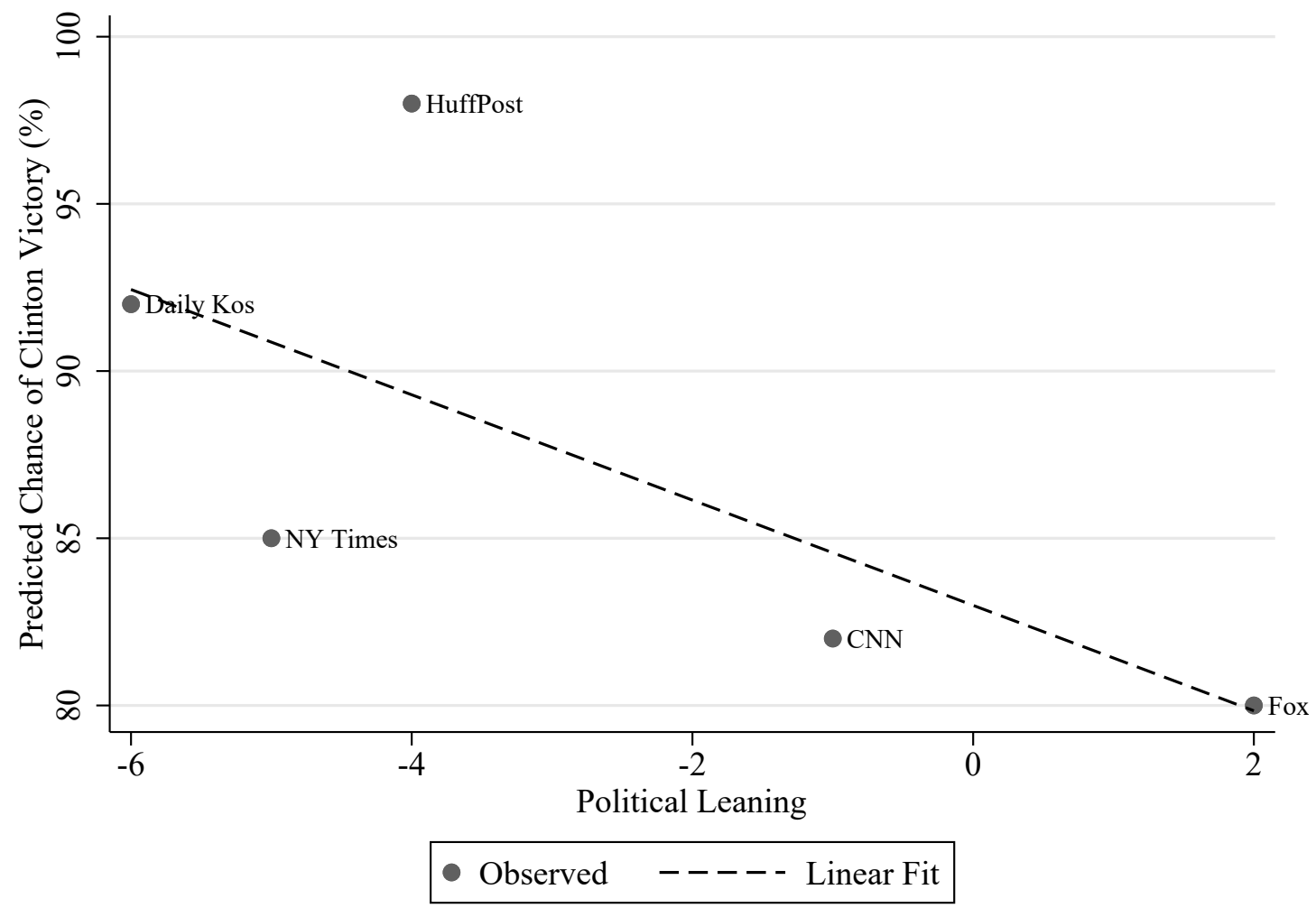

Notes: Estimated Probability of a Clinton victory in the 2016 Presidential Elections reported by media outlets on Election Day, plotted against the slant of the media outlet. Positive values of Political Leaning indicate pro-Trump bias. Media slant of outlets other than the Daily Kos is based on Pew data ${ }^{45}$. Media slant of the Daily Kos is estimated using Quantcast ${ }^{46}$, Fact Check / New York Times ${ }^{47}$, Media Bias Fact Check ${ }^{48}$, and Fake News Checker ${ }^{49}$.

\footnotetext{
${ }^{1}$ http://www . journalism.org/2014/10/21/political-polarization-media-habits/

${ }^{2}$ https://www. quantcast . com/dailykos. com\#demographicsCard

${ }^{3}$ http://www.nytimes.com/2010/04/05/technology/05snopes.html

${ }^{4}$ https://mediabiasfactcheck.com/daily-kos/

${ }^{5}$ http://www.fakenewschecker.com/fake-news-source/daily-kos
} 
TABle A.1: List of Most Important Votes by Election Day

\begin{tabular}{|c|c|c|c|}
\hline Date & Title & Turnout $(\%)$ & Yes $(\%)$ \\
\hline 1981-06-14 & Initiative for "Equal Rights of Men and Women" & 33.95 & 60.27 \\
\hline 1981-11-29 & Federal Decision on the Financial Order Improving the Federal Budget & 30.35 & 68.95 \\
\hline 1982-06-06 & Federal Penal Code (Violent Crime) & 35.19 & 63.71 \\
\hline $1982-11-28$ & Initiative for "Preventing Abusive Pricing" & 32.93 & 57.94 \\
\hline 1983-02-27 & Federal Decision on the Revision of Fuel Tariffs & 32.42 & 52.69 \\
\hline 1983-12-04 & Federal Decision on the Regulation of Citzenship in the Constitution & 35.84 & 60.81 \\
\hline 1984-02-26 & Initiative "for Civil Service Based on Factual Evidence" & 52.77 & 36.17 \\
\hline 1984-05-20 & Initiative "against Bank Secrecy and the Power of Banks" & 42.52 & 26.96 \\
\hline 1984-09-23 & Initiative "for a Safe, Economical and Eco-Friendly Energy" & 41.62 & 45.77 \\
\hline 1984-12-02 & Initiative "for an Effective Protection of Motherhood" & 37.66 & 15.78 \\
\hline 1985-03-10 & Initiative "for Extending Paid Holidays" & 34.60 & 34.78 \\
\hline 1985-06-09 & Initiative "for the Right to Life" & 35.72 & 30.96 \\
\hline 1985-09-22 & Federal Decision on Risk Guarantees for Innovations in SMEs & 40.87 & 43.11 \\
\hline 1985-12-01 & Initiative "for Abolishing Vivisection" & 37.97 & 29.47 \\
\hline 1986-03-16 & Federal Decision on the Accession to the United Nations & 50.71 & 24.33 \\
\hline 1986-09-28 & Initiative "for Secured Vocational Education and Re-training" & 34.82 & 18.38 \\
\hline 1986-12-07 & Initiative "for an Fair Levy on Heavy Traffic" & 34.74 & 33.87 \\
\hline 1987-04-05 & Initiative "for Referenda against Military Expenses" & 42.42 & 40.56 \\
\hline 1987-12-06 & Federal Decision on "Railway 2000" & 47.70 & 56.99 \\
\hline 1988-06-12 & Initiative "for Reducing the Retirement Age" & 42.02 & 35.12 \\
\hline 1988-12-04 & Initiative "against Land Speculation" & 52.83 & 30.78 \\
\hline 1989-06-04 & Initiative "for Natural Farming - against Animal Factories" & 35.96 & 48.95 \\
\hline 1989-11-26 & Initiative "for Switzerland Without an Army and a Comprehensive Peace Policy" & 69.19 & 35.59 \\
\hline 1990-04-01 & Initiative "against Concrete - for Limiting Road Construction" & 41.13 & 28.51 \\
\hline 1990-09-23 & Initiative "against Constructing New Nuclear Power Plants" & 40.44 & 54.52 \\
\hline 1991-03-03 & Initiative "for Promoting Public Transport" & 31.24 & 37.14 \\
\hline 1991-06-02 & Federal Decision on Federal Budget Reform & 33.27 & 45.65 \\
\hline 1992-02-16 & Initiative "for the Drastic and Stepwise Limitation of Animal Experiments" & 44.50 & 43.63 \\
\hline
\end{tabular}

Continued on next page 
Continued from previous page

\begin{tabular}{|c|c|c|c|}
\hline Date & Vote Title & Turnout $(\%)$ & Yes $(\%)$ \\
\hline 1992-05-17 & Initiative "against Abuses of Reproduction Technology and Genetic Engeneering" & 39.18 & 73.83 \\
\hline 1992-09-27 & Federal Decision on the New Railway Link through the Alps (NRLA) & 45.91 & 63.61 \\
\hline 1992-12-06 & Federal Act on the Accession to the European Economic Area & 78.78 & 49.66 \\
\hline 1993-03-07 & Initiative "for Abolishing Animal Experiments" & 51.26 & 27.77 \\
\hline 1993-06-06 & Initiative "for Switzerland without New Fighter Jets" & 55.61 & 42.81 \\
\hline 1993-09-26 & Federal Decision on Temporary Measures against Cost Increases in Health Care & 39.80 & 80.55 \\
\hline 1993-11-28 & Initiative "for Reducing Alcohol Problems" & 45.51 & 25.26 \\
\hline 1994-02-20 & Initiative "for Protecting the Alpine Region against Transit Traffic" & 40.86 & 51.91 \\
\hline 1994-06-12 & Federal Decision on the Facilitated Naturalization for Young Foreign Nationals & 46.78 & 52.84 \\
\hline 1994-09-25 & Federal Penal Code and Military Penal Code (Racial Discrimination) & 45.93 & 54.65 \\
\hline 1994-12-04 & Federal Act on Coercive Measures under the Law on Foreigners & 44.06 & 72.91 \\
\hline 1995-03-12 & Federal Decision on Curbing Expenditures & 37.88 & 83.38 \\
\hline $1995-06-25$ & Federal Act on Old Age Insurance & 40.45 & 60.71 \\
\hline 1996-03-10 & Federal Decision Abolishing Cantonal Responsibility for the Equipment of Soldiers & 31.04 & 43.70 \\
\hline 1996-06-09 & Initiative "Farmers and Consumers - for a natural Agriculture" (counter-proposal) & 31.44 & 77.59 \\
\hline 1996-12-01 & Federal Act on Labor & 46.76 & 32.97 \\
\hline $1997-06-08$ & Initiative "for a Ban on Exports of War Material" & 35.50 & 22.50 \\
\hline 1997-09-28 & Federal Decision on the Financing of the Unemployment Insurance & 40.65 & 49.18 \\
\hline 1998-06-07 & Initiative "for Protecting Life and Environment from Genetic Engeneering" & 41.35 & 33.29 \\
\hline 1998-09-27 & Federal Act on Power-Dependent Levies on Heavy Traffic & 51.85 & 57.20 \\
\hline $1998-11-29$ & Initiative "for a Reasonable Drug Policy" & 38.39 & 26.01 \\
\hline 1999-02-07 & Federal Decision on a Constitutional Article on Transplant Medicine & 38.01 & 87.77 \\
\hline 1999-04-18 & Federal Decision on a New Constitution & 35.93 & 59.16 \\
\hline 1999-06-13 & Federal Decision on Maternity Insurance & 45.98 & 38.99 \\
\hline $2000-03-12$ & Initiative "for Halving Motorised Traffic and Conserving Habitats" & 42.41 & 21.33 \\
\hline $2000-05-21$ & Federal Decision on Bilateral Treaties between Switzerland and the EU & 48.35 & 67.19 \\
\hline 2000-09-24 & Initiative "for Regulating Immigration" & 45.31 & 36.20 \\
\hline 2000-11-26 & Initiative "for Lower Hospital Costs" & 41.69 & 17.89 \\
\hline 2001-03-04 & Initiative "Yes to Europe!" & 55.84 & 23.15 \\
\hline 2001-06-10 & Federal Act on the Army and Military Administration (Armament) & 42.55 & 50.99 \\
\hline
\end{tabular}


Continued from previous page

\begin{tabular}{|c|c|c|c|}
\hline Date & Vote Title & Turnout $(\%)$ & Yes $(\%)$ \\
\hline 2001-12-02 & Initiative "for a Credible Security Policy and Switzerland without an Army" & 37.96 & 21.90 \\
\hline 2002-03-03 & Initiative "for Accession to the UN" & 58.48 & 54.61 \\
\hline 2002-06-02 & Federal Penal Code (Abortion) & 41.85 & 72.15 \\
\hline 2002-09-22 & Initiative "Gold Reserves for the Old Age Insurance" & 45.21 & 47.56 \\
\hline 2002-11-24 & Initiative "against Abuse of Asylum" & 47.97 & 49.91 \\
\hline 2003-02-09 & Federal Act on Adjusting Cantonal Contributions to Hospitals & 28.74 & 77.36 \\
\hline 2003-05-18 & Initiative "Energy without Nuclear Power - For a Stepwise Phaseout" & 49.77 & 33.71 \\
\hline 2004-02-08 & Initiative "Liefelong Custody for Untreatable, Extremely Dangerous Offenders" & 45.54 & 56.19 \\
\hline 2004-05-16 & Federal Act on Tax Refrom and Revision Stamp Duties & 50.85 & 34.12 \\
\hline 2004-09-26 & Federal Act on Compensation for Loss of Earings (Motherhood) & 53.82 & 55.45 \\
\hline 2004-11-28 & Federal Act on Stem Cell Research & 37.04 & 66.39 \\
\hline 2005-06-05 & Federal Decision on the Association to the EU Schengen-Dublin Agreements & 56.64 & 54.63 \\
\hline 2005-09-25 & Federal Decision Extending Free Movement of Persons to New EU Member States & 54.29 & 55.98 \\
\hline $2005-11-27$ & Initiative "Initiative for GMO-Free Agriculture" & 42.25 & 55.67 \\
\hline 2006-05-21 & Federal Decision on Revising Constituional Provisions for Education & 27.80 & 85.58 \\
\hline 2006-09-24 & Federal Act on Asylum & 48.92 & 67.76 \\
\hline 2006-11-26 & Federal Act on Family Allowances & 45.01 & 67.98 \\
\hline 2007-03-11 & Initiative "for a Unified Social Health Insurance" & 45.94 & 28.76 \\
\hline 2007-06-17 & Federal Act on Disability Insurance & 36.20 & 59.09 \\
\hline 2008-02-24 & Federal Act on Corporate Tax Reform & 38.63 & 50.53 \\
\hline 2008-06-01 & Initiative "for Democratic Naturalizations" & 45.18 & 36.25 \\
\hline 2008-11-30 & Initiative "for a Flexible Retirement Age" & 47.67 & 41.38 \\
\hline 2009-02-08 & Federal Decision Extending Free Movement of Persons to New EU Members & 51.44 & 59.61 \\
\hline 2009-05-17 & Initiative "Yes to Complementary Medicine" (counter-proposal) & 38.80 & 67.03 \\
\hline 2009-09-27 & Federal Decision on Funding the Disability Insurance by Raising the VAT & 41.01 & 54.56 \\
\hline 2009-11-29 & Initiative "against the Construction of Minarets" & 53.76 & 57.50 \\
\hline 2010-03-07 & Federal Act on the Occupational Pension Scheme & 45.75 & 27.27 \\
\hline 2010-09-26 & Federal Act on the Unemployment Insurance & 35.84 & 53.42 \\
\hline $2010-11-28$ & Initiative "for the Expulsion of Criminal Foreign Nationals" & 52.93 & 52.91 \\
\hline 2011-02-13 & Initiative "for Protection against Armed Violence" & 49.12 & 43.70 \\
\hline
\end{tabular}

Continued on next page 
Continued from previous page

\begin{tabular}{|c|c|c|c|}
\hline Date & Vote Title & Turnout $(\%)$ & Yes $(\%)$ \\
\hline 2012-03-11 & Initiative "Limiting the Construction of Second Homes" & 45.18 & 50.63 \\
\hline 2012-06-17 & Federal Act on Health Insurance (Managed Care) & 38.65 & 23.95 \\
\hline 2012-09-23 & Federal Decision on a Constitutional Article Promoting Music Lessons for the Young & 42.42 & 72.69 \\
\hline 2012-11-25 & Federal Act on Epizootic Diseases & 27.60 & 68.28 \\
\hline 2013-03-03 & Initiative "against Rip-Off Salaries" & 46.74 & 67.96 \\
\hline 2013-06-09 & Federal Act on Asylum & 39.43 & 78.45 \\
\hline 2013-09-22 & Initiative "Repealing Compulsory Military Service" & 46.89 & 26.79 \\
\hline 2013-11-24 & Federal Act on Tolls for the Use of National Roads & 53.61 & 39.54 \\
\hline 2014-02-09 & Initiative "against Mass Immigration" & 56.57 & 50.33 \\
\hline 2014-05-18 & Initiative "for Protecting Fair Wages (Minimum Wage Initative)" & 56.36 & 23.73 \\
\hline 2014-09-28 & Initiative "for a Public Health Insurance" & 47.18 & 38.16 \\
\hline 2014-11-30 & Initiative "Stop Overpopulation - for Securing Natural Life Resources" & 49.98 & 25.90 \\
\hline 2015-03-08 & Initiative "for an Energy Tax Instaed of the Value Added Tax" & 42.06 & 8.03 \\
\hline 2015-06-14 & Initiative "for Bequest Taxes on the Wealthy for Funding the Old Age Insurance" & 43.71 & 28.96 \\
\hline 2016-02-28 & Initiative "for Enforcing the Expulsion of Criminal Foreign Nationals" & 63.73 & 41.15 \\
\hline 2016-06-05 & Federal Act on Asylum & 46.79 & 66.78 \\
\hline 2016-09-25 & Initiative "for a Stronger Old Age Insurance" & 43.13 & 40.60 \\
\hline 2016-11-27 & Initiative "for a Structured Nuclear Phaseout" & 45.38 & 45.80 \\
\hline 2017-02-12 & Federal Decision on Facilitaed Naturalization of Third Generation Foreign Nationals & 46.84 & 60.41 \\
\hline 2017-05-21 & Federal Act on Energy & 42.89 & 58.22 \\
\hline 2017-09-24 & Federal Act on the Old Age Insurance Reform 2020 & 47.39 & 47.31 \\
\hline 2018-03-04 & Initiative "for Abolishing Radio and Television Fees" & 54.84 & 28.44 \\
\hline 2018-06-10 & Initiative "for Crisis-Proof Money: Money Creation Only by the Central Bank" & 34.55 & 24.28 \\
\hline 2018-09-23 & Initiative "for Healthy, Environmentally Friendly and Fair Food" & 37.52 & 38.70 \\
\hline $2018-11-25$ & Federal Act on Social Insurance & 48.38 & 64.72 \\
\hline 2019-02-10 & Initiative "against Urban Sprawling - for a Sustainable Settlement Development" & 37.92 & 36.34 \\
\hline 2019-05-19 & Federal Act on Tax Reform and Funding for Old Age Insurance & 43.74 & 66.38 \\
\hline
\end{tabular}


TAble A.2: List of Newspapers Consulted for Poll Coverage And Political Ads

\begin{tabular}{|c|c|c|}
\hline Newspaper & Language & $\begin{array}{c}\text { \# of cantons for which it } \\
\text { has been used }\end{array}$ \\
\hline Aargauer Zeitung & German & 1 \\
\hline Badener Woche & German & 1 \\
\hline Basellandschaftl. Ztg. & German & 1 \\
\hline Basler Zeitung & German & 2 \\
\hline Berner Zeitung & German & 2 \\
\hline Blick & German & 20 \\
\hline Blick am Abend & German & 15 \\
\hline Bund & German & 1 \\
\hline Büwo & German & 1 \\
\hline Caffè della domenica (Il) & Italian & 1 \\
\hline Corriere del Ticino & Italian & 1 \\
\hline Côte (La) & French & 1 \\
\hline Engadiner Post & German & 1 \\
\hline (L')Express (aggregated with L'Impartial) & French & 1 \\
\hline Freiburger Nachrichten & German & 1 \\
\hline Giornale del Popolo & Italian & 1 \\
\hline Gruyère (La) & French & 1 \\
\hline Liberté (La) & French & 1 \\
\hline Matin (Le) & French & 6 \\
\hline Matin Dimanche (Le) & French & 6 \\
\hline Matin Bleu (Le) & French & 6 \\
\hline Mattino della Domenica (Il) & Italian & 1 \\
\hline $\begin{array}{l}\text { Neue Luzerner Zeitung GES (sometimes aggre- } \\
\text { gated with: Neue Nidwaldner Zeitung; Neue Obwaldner } \\
\text { Zeitung; Neue Schwyzer Zeitung; Neue Urner Zeitung; } \\
\text { Neue Zuger Zeitung) }\end{array}$ & German & 6 \\
\hline Nouvelliste (Le) & French & 1 \\
\hline $\mathrm{NZZ}$ & German & 3 \\
\hline NZZ am Sonntag & German & 14 \\
\hline Ostschweiz am Sonntag & German & 4 \\
\hline Quotidien Jurassien (Le) & French & 1 \\
\hline Regione Ticino (La) & Italian & 1 \\
\hline Rheinzeitung & German & 2 \\
\hline Schaffhauser Nachrichten & German & 1 \\
\hline Sonntag (Schweiz am Sonntag from 2013) & German & 5 \\
\hline Sonntags Blick & German & 21 \\
\hline Sonntags Zeitung & German & 19 \\
\hline $\begin{array}{l}\text { St. Galler Tagblatt (sometimes aggregated with: Ap- } \\
\text { penzeller Zeitung) }\end{array}$ & German & 5 \\
\hline Südostschweiz GES (Die) & German & 4 \\
\hline Südostschweiz am Sonntag & German & 1 \\
\hline
\end{tabular}

Continued on next page 


\begin{tabular}{lcc} 
& \multicolumn{2}{c}{ Continued from previous page } \\
\hline Newspaper & Language & $\begin{array}{c}\text { \# of cantons for which it } \\
\text { has been used }\end{array}$ \\
\hline Tages-Anzeiger & German & 7 \\
Temps (Le) & French & 2 \\
Thurgauer Zeitung & German & 1 \\
Tribune de Genève & French & 1 \\
Walliser Bote & German & 1 \\
Wiler Zeitung & German & 1 \\
Zentralschweiz am Sonntag & German & 5 \\
Zuger Woche & German & 1 \\
Zürichsee Zeitung & German & 1 \\
20 Minuten & German & 19 \\
20 Minutes & French & 6 \\
20 Minuti & Italian & 1 \\
24 Heures & French & 1 \\
\hline \hline
\end{tabular}


Table A.3: Daily Turnout Before and After Poll Release Depending on Poll Closeness: Single Days

\begin{tabular}{|c|c|c|c|c|c|c|}
\hline & \multicolumn{2}{|c|}{ Net Turnout $(\%)$} & \multicolumn{2}{|c|}{ Turnout / All Voters (\%) } & \multicolumn{2}{|c|}{ Log(Turnout) } \\
\hline & (1) & $(2)$ & (3) & $(4)$ & (5) & (6) \\
\hline 5 days before poll $\times$ Ex Ante Closeness (std.) & $\begin{array}{c}0.0429 \\
(0.3879)\end{array}$ & $\begin{array}{c}-0.0154 \\
(0.3902)\end{array}$ & $\begin{array}{c}-0.0614 \\
(0.3580)\end{array}$ & $\begin{array}{c}-0.1186 \\
(0.3583)\end{array}$ & $\begin{array}{c}0.0973 \\
(0.2203)\end{array}$ & $\begin{array}{c}0.0767 \\
(0.2239)\end{array}$ \\
\hline 4 days before poll $\times$ Ex Ante Closeness (std.) & $\begin{array}{c}0.0288 \\
(0.3348)\end{array}$ & $\begin{array}{c}-0.0684 \\
(0.3300)\end{array}$ & $\begin{array}{c}-0.0571 \\
(0.3053)\end{array}$ & $\begin{array}{c}-0.1431 \\
(0.2981)\end{array}$ & $\begin{array}{c}0.0031 \\
(0.1592)\end{array}$ & $\begin{array}{c}-0.0324 \\
(0.1532)\end{array}$ \\
\hline 3 days before poll $\times E x$ Ante Closeness (std.) & $\begin{array}{c}0.1241 \\
(0.2872)\end{array}$ & $\begin{array}{c}0.0278 \\
(0.2920)\end{array}$ & $\begin{array}{c}0.0562 \\
(0.2676)\end{array}$ & $\begin{array}{c}-0.0381 \\
(0.2703)\end{array}$ & $\begin{array}{c}-0.0147 \\
(0.1437)\end{array}$ & $\begin{array}{l}-0.0390 \\
(0.1464)\end{array}$ \\
\hline 2 days before poll $\times E x$ Ante Closeness (std.) & $\begin{array}{c}0.0579 \\
(0.2775)\end{array}$ & $\begin{array}{c}0.0864 \\
(0.2860)\end{array}$ & $\begin{array}{c}0.0003 \\
(0.2526)\end{array}$ & $\begin{array}{c}0.0241 \\
(0.2593)\end{array}$ & $\begin{array}{c}-0.0051 \\
(0.1144)\end{array}$ & $\begin{array}{c}0.0057 \\
(0.1186)\end{array}$ \\
\hline 1 day before poll $\times$ Ex Ante Closeness (std.) & $\begin{array}{c}-0.0667 \\
(0.1841)\end{array}$ & $\begin{array}{c}-0.0591 \\
(0.1900)\end{array}$ & $\begin{array}{c}-0.0712 \\
(0.1496)\end{array}$ & $\begin{array}{c}-0.0658 \\
(0.1532)\end{array}$ & $\begin{array}{c}0.0088 \\
(0.0542)\end{array}$ & $\begin{array}{c}0.0142 \\
(0.0560)\end{array}$ \\
\hline 1 day after poll $\times E x$ Ante Closeness (std.) & $\begin{array}{c}0.3926^{* *} \\
(0.1743)\end{array}$ & $\begin{array}{c}0.3731^{* *} \\
(0.1753)\end{array}$ & $\begin{array}{c}0.3088^{* *} \\
(0.1343)\end{array}$ & $\begin{array}{c}0.2931^{* *} \\
(0.1352)\end{array}$ & $\begin{array}{l}0.1131^{*} \\
(0.0588)\end{array}$ & $\begin{array}{c}0.1101^{*} \\
(0.0602)\end{array}$ \\
\hline 2 days after poll $\times$ Ex Ante Closeness (std.) & $\begin{array}{c}0.3534^{* *} \\
(0.1741)\end{array}$ & $\begin{array}{c}0.3289^{*} \\
(0.1770)\end{array}$ & $\begin{array}{c}0.2422 \\
(0.1457)\end{array}$ & $\begin{array}{c}0.2267 \\
(0.1502)\end{array}$ & $\begin{array}{l}0.1218^{* *} \\
(0.0560)\end{array}$ & $\begin{array}{c}0.1162^{* *} \\
(0.0572)\end{array}$ \\
\hline 3 days after poll $\times E x$ Ante Closeness (std.) & $\begin{array}{c}0.4253^{* *} \\
(0.2052)\end{array}$ & $\begin{array}{c}0.4438^{* *} \\
(0.2107)\end{array}$ & $\begin{array}{c}0.2853^{*} \\
(0.1652)\end{array}$ & $\begin{array}{c}0.2998^{*} \\
(0.1696)\end{array}$ & $\begin{array}{c}0.1048^{*} \\
(0.0594)\end{array}$ & $\begin{array}{c}0.1120^{*} \\
(0.0623)\end{array}$ \\
\hline 4 days after poll $\times E x$ Ante Closeness (std.) & $\begin{array}{c}0.2247 \\
(0.2619)\end{array}$ & $\begin{array}{c}0.1996 \\
(0.2707)\end{array}$ & $\begin{array}{c}0.1279 \\
(0.2319)\end{array}$ & $\begin{array}{c}0.1117 \\
(0.2421)\end{array}$ & $\begin{array}{c}0.0777 \\
(0.0774)\end{array}$ & $\begin{array}{c}0.0770 \\
(0.0813)\end{array}$ \\
\hline 5 days after poll $\times E x$ Ante Closeness (std.) & $\begin{array}{c}0.3014 \\
(0.2061)\end{array}$ & $\begin{array}{c}0.3219 \\
(0.2111)\end{array}$ & $\begin{array}{c}0.1654 \\
(0.1801)\end{array}$ & $\begin{array}{c}0.1799 \\
(0.1852)\end{array}$ & $\begin{array}{c}0.0946 \\
(0.0636)\end{array}$ & $\begin{array}{c}0.1024 \\
(0.0660)\end{array}$ \\
\hline 6 days after poll $\times$ Ex Ante Closeness (std.) & $\begin{array}{c}0.0805 \\
(0.3072)\end{array}$ & $\begin{array}{c}0.0773 \\
(0.3103)\end{array}$ & $\begin{array}{c}0.0168 \\
(0.2463)\end{array}$ & $\begin{array}{c}0.0152 \\
(0.2515)\end{array}$ & $\begin{array}{c}0.0678 \\
(0.0751)\end{array}$ & $\begin{array}{c}0.0693 \\
(0.0779)\end{array}$ \\
\hline 7 days after poll $\times E x$ Ante Closeness (std.) & $\begin{array}{c}0.3365 \\
(0.3158)\end{array}$ & $\begin{array}{c}0.3503 \\
(0.3220)\end{array}$ & $\begin{array}{c}0.1722 \\
(0.2605)\end{array}$ & $\begin{array}{c}0.1840 \\
(0.2665)\end{array}$ & $\begin{array}{c}0.1037 \\
(0.0854)\end{array}$ & $\begin{array}{c}0.1097 \\
(0.0883)\end{array}$ \\
\hline 8 days after poll $\times E x$ Ante Closeness (std.) & $\begin{array}{c}0.0594 \\
(0.3561)\end{array}$ & $\begin{array}{c}0.0551 \\
(0.3562)\end{array}$ & $\begin{array}{c}0.0115 \\
(0.2625)\end{array}$ & $\begin{array}{c}0.0102 \\
(0.2645)\end{array}$ & $\begin{array}{c}0.0574 \\
(0.0818)\end{array}$ & $\begin{array}{c}0.0604 \\
(0.0839)\end{array}$ \\
\hline 9 days after poll $\times E x$ Ante Closeness (std.) & $\begin{array}{c}0.4430 \\
(0.3354)\end{array}$ & $\begin{array}{c}0.4018 \\
(0.3303)\end{array}$ & $\begin{array}{c}0.2324 \\
(0.2468)\end{array}$ & $\begin{array}{c}0.2071 \\
(0.2477)\end{array}$ & $\begin{array}{c}0.1135 \\
(0.0797)\end{array}$ & $\begin{array}{c}0.1109 \\
(0.0816)\end{array}$ \\
\hline R-squared & 0.488 & 0.511 & 0.300 & 0.330 & 0.235 & 0.258 \\
\hline Observations & 757 & 757 & 757 & 757 & 757 & 757 \\
\hline Vote Fixed Effects & $\mathrm{Y}$ & $\mathrm{Y}$ & $\mathrm{Y}$ & $\mathrm{Y}$ & $\mathrm{Y}$ & $\mathrm{Y}$ \\
\hline Voting Day from/to Poll Fixed Effects & $\mathrm{Y}$ & $\mathrm{Y}$ & $\mathrm{Y}$ & $\mathrm{Y}$ & $\mathrm{Y}$ & $\mathrm{Y}$ \\
\hline Day to Vote Fixed Effects & $\mathrm{N}$ & $\mathrm{Y}$ & $\mathrm{N}$ & $\mathrm{Y}$ & $\mathrm{N}$ & $\mathrm{Y}$ \\
\hline
\end{tabular}

Notes: The table presents OLS estimates with three measures of daily turnout in Geneva as dependent variables: Net Turnout (columns 1 and 2) defined as the number of votes cast, in percent of eligible voters net of those voters who cast their vote on earlier days; Turnout / All Voters (columns 3 and 4) defined as the number of votes cast, in percent of all eligible voters; Log(Turnout) (columns 5 and 6) defined as the natural logarithm of the number of votes cast. Ex Ante Closeness is the losing side's vote share predicted by the pre-election poll whose release date is the omitted day of reference. The sample is an unbalanced panel of 52 votes held between 2001 and 2019 observed from 5 voting days before to 9 voting days after poll release. Standard errors in parentheses, clustered at the vote level: ${ }^{*} p<0.10,{ }^{* *} p<0.05,{ }^{* * *} p<0.01$. 
Table A.4: Daily Turnout Before and After Poll Release Depending on Poll Closeness: Bins of Two Days

\begin{tabular}{|c|c|c|c|c|c|c|}
\hline & \multicolumn{2}{|c|}{ Net Turnout (\%) } & \multicolumn{2}{|c|}{ Turnout / All Voters (\%) } & \multicolumn{2}{|c|}{ Log(Turnout) } \\
\hline & (1) & (2) & (3) & (4) & (5) & $(6)$ \\
\hline 4-5 days before poll $\times$ Ex Ante Closeness (std.) & $\begin{array}{c}0.0690 \\
(0.2808)\end{array}$ & $\begin{array}{l}-0.0126 \\
(0.2766)\end{array}$ & $\begin{array}{l}-0.0237 \\
(0.2638)\end{array}$ & $\begin{array}{l}-0.0978 \\
(0.2574)\end{array}$ & $\begin{array}{c}0.0451 \\
(0.1618)\end{array}$ & $\begin{array}{c}0.0145 \\
(0.1584)\end{array}$ \\
\hline 2-3 days before poll $\times E x$ Ante Closeness (std.) & $\begin{array}{c}0.1243 \\
(0.2085)\end{array}$ & $\begin{array}{c}0.0873 \\
(0.2111)\end{array}$ & $\begin{array}{c}0.0638 \\
(0.2005)\end{array}$ & $\begin{array}{c}0.0266 \\
(0.2025)\end{array}$ & $\begin{array}{l}-0.0143 \\
(0.1124)\end{array}$ & $\begin{array}{c}-0.0231 \\
(0.1148)\end{array}$ \\
\hline 1-2 days after poll $\times$ Ex Ante Closeness (std.) & $\begin{array}{c}0.4063^{* * *} \\
(0.1440)\end{array}$ & $\begin{array}{c}0.3806^{* * *} \\
(0.1417)\end{array}$ & $\begin{array}{c}0.3111^{* * *} \\
(0.1054)\end{array}$ & $\begin{array}{c}0.2929^{* * *} \\
(0.1044)\end{array}$ & $\begin{array}{c}0.1130^{* * *} \\
(0.0412)\end{array}$ & $\begin{array}{c}0.1061^{* *} \\
(0.0403)\end{array}$ \\
\hline 3-4 days after poll $\times$ Ex Ante Closeness (std.) & $\begin{array}{c}0.3584^{* *} \\
(0.1422)\end{array}$ & $\begin{array}{c}0.3512^{* *} \\
(0.1457)\end{array}$ & $\begin{array}{c}0.2422^{*} \\
(0.1285)\end{array}$ & $\begin{array}{c}0.2387^{*} \\
(0.1335)\end{array}$ & $\begin{array}{l}0.0868^{*} \\
(0.0434)\end{array}$ & $\begin{array}{c}0.0875^{*} \\
(0.0459)\end{array}$ \\
\hline 5-6 days after poll $\times$ Ex Ante Closeness (std.) & $\begin{array}{c}0.2243 \\
(0.1853)\end{array}$ & $\begin{array}{c}0.2292 \\
(0.1856)\end{array}$ & $\begin{array}{c}0.1267 \\
(0.1556)\end{array}$ & $\begin{array}{c}0.1305 \\
(0.1580)\end{array}$ & $\begin{array}{c}0.0768 \\
(0.0468)\end{array}$ & $\begin{array}{c}0.0789 \\
(0.0484)\end{array}$ \\
\hline 7-9 days after poll $\times E x$ Ante Closeness (std.) & $\begin{array}{c}0.3088 \\
(0.2630)\end{array}$ & $\begin{array}{c}0.2952 \\
(0.2638)\end{array}$ & $\begin{array}{c}0.1719 \\
(0.2003)\end{array}$ & $\begin{array}{c}0.1648 \\
(0.2028)\end{array}$ & $\begin{array}{c}0.0866 \\
(0.0597)\end{array}$ & $\begin{array}{c}0.0862 \\
(0.0615)\end{array}$ \\
\hline R-squared & 0.486 & 0.509 & 0.298 & 0.327 & 0.233 & 0.256 \\
\hline Observations & 757 & 757 & 757 & 757 & 757 & 757 \\
\hline Vote Fixed Effects & Y & $\mathrm{Y}$ & $\mathrm{Y}$ & $\mathrm{Y}$ & $\mathrm{Y}$ & Y \\
\hline Voting Day from/to Poll Fixed Effects & $\mathrm{Y}$ & $\mathrm{Y}$ & $\mathrm{Y}$ & $\mathrm{Y}$ & $\mathrm{Y}$ & $\mathrm{Y}$ \\
\hline Day to Vote Fixed Effects & $\mathrm{N}$ & $\mathrm{Y}$ & $\mathrm{N}$ & $\mathrm{Y}$ & $\mathrm{N}$ & $\mathrm{Y}$ \\
\hline
\end{tabular}

Notes: The table presents OLS estimates with three measures of daily turnout in Geneva as dependent variables: Net Turnout (columns 1 and 2) defined as the number of votes cast, in percent of eligible voters net of those voters who cast their vote on earlier days; Turnout / All Voters (columns 3 and 4) defined as the number of votes cast, in percent of all eligible voters; Log(Turnout) (columns 5 and 6) defined as the natural logarithm of the number of votes cast. Ex Ante Closeness is the losing side's vote share predicted by the pre-election poll whose release date (and the preceding day) are the omitted days of reference. The sample is an unbalanced panel of 52 votes held between 2001 and 2019 observed from 5 voting days before to 9 voting days after poll release. Standard errors in parentheses, clustered at the vote level: ${ }^{*} p<0.10,{ }^{* *} p<0.05,{ }^{* * *} p<0.01$. 
Table A.5: Heterogeneous Effects of Election Closeness and Polls Depending on Municipality POLITICAL HOMOGENEITY

\begin{tabular}{lcc}
\hline \hline & $(1)$ & $(2)$ \\
\hline Ex Post Closeness (std.) $\times$ Homogeneity (std.) & $-0.5674^{* * *}$ & $-0.5659^{* * *}$ \\
& $(0.1900)$ & $(0.1904)$ \\
Ex Post Closeness (std.) $\times$ Homogeneity (std.) $\times$ Poll Era & $0.5874^{* *}$ & $0.5822^{* *}$ \\
& $(0.2631)$ & $(0.2630)$ \\
Homogeneity (std.) $\times$ Poll Era & $2.3689^{* * *}$ & $2.3936^{* * *}$ \\
& $(0.2319)$ & $(0.2319)$ \\
\hline Test for Convergence (p-value) & 0.913 & 0.928 \\
\hline R-squared & 0.700 & 0.700 \\
Observations & 250240 & 250240 \\
Municipality Fixed Effects & $\mathrm{Y}$ & $\mathrm{Y}$ \\
Vote Fixed Effects & $\mathrm{Y}$ & $\mathrm{Y}$ \\
Electorate Size & $\mathrm{N}$ & $\mathrm{Y}$ \\
\hline \hline
\end{tabular}

Notes: Each column presents results from an OLS regression with municipality-level voter turnout as the dependent variable. Political Homogeneity is a municipalitiy's historical tendency to produce voting results distant from 50-50, as measured by the average municipal-level margin of majority across all votes held in the era before pre-election polls. Poll Era is a dummy equal to 1 for 69 votes held after the introduction of polls in 1998. Test for Convergence reports the p-value of an F-test that the sum of the coefficients on Ex Post Closeness (std.) $\times$ Homogeneity (std.) and Ex Post Closeness (std.) $\times$ Homogeneity (std.) $\times$ Poll Era (std.) equals 0 . Column 2 controls for a triple interaction among Ex Post Closeness, Poll Era and the standardized average municipality electorate size, as well as all lower order terms. The sample is a balanced panel of 2176 municipalities observed in 115 votes held from 1981 to 2019. Standard errors clustered at the vote level in parentheses: ${ }^{*} p<0.10,{ }^{* *} p<0.05,{ }^{* * *} p<0.01$. 
Table A.6: Newspaper Coverage, Closeness and Cantonal Voter Turnout: IV Estimates

\begin{tabular}{|c|c|c|c|}
\hline & \multicolumn{2}{|r|}{ First Stage } & \multirow{2}{*}{$\begin{array}{c}\text { Second Stage } \\
(3) \\
\text { Turnout }\end{array}$} \\
\hline & $\begin{array}{c}(1) \\
\text { Poll Mentions (std.) }\end{array}$ & $\begin{array}{c}(2) \\
\text { Poll Mentions (std.) } \times \text { Ex Ante Closeness (std.) }\end{array}$ & \\
\hline Incidental Poll Mentions (std.) $\times$ Ex Ante Closeness (std.) & $\begin{array}{c}0.0231 \\
(0.0392)\end{array}$ & $\begin{array}{c}0.3880^{* * *} \\
(0.0433)\end{array}$ & \\
\hline Incidental Poll Mentions (std.) & $\begin{array}{c}0.7351^{* * *} \\
(0.0397)\end{array}$ & $\begin{array}{l}0.1020^{*} \\
(0.0578)\end{array}$ & \\
\hline Poll Mentions (std.) × Ex Ante Closeness (std.) & & & $\begin{array}{l}0.9789^{* *} \\
(0.4790)\end{array}$ \\
\hline Poll Mentions (std.) & & & $\begin{array}{l}-0.2472 \\
(0.3788)\end{array}$ \\
\hline R-squared & 0.866 & 0.699 & 0.819 \\
\hline Observations & 962 & 962 & 962 \\
\hline $\begin{array}{l}\text { Test Joint Significance Excluded Instruments } \\
\text { Test } \beta \text { (Incidental Poll Mentions) } \geq 1\end{array}$ & $\begin{array}{l}\mathrm{p}<0.0001 \\
\mathrm{p}<0.0001\end{array}$ & $\mathrm{p}<0.0001$ & \\
\hline
\end{tabular}

